\title{
Biomarkers of tumor invasiveness in proteomics (Review)
}

\author{
DANIEL L. POULIQUEN ${ }^{1}$, ALICE BOISSARD ${ }^{2}$, OLIVIER COQUERET ${ }^{1}$ and CATHERINE GUETTE ${ }^{2}$ \\ ${ }^{1}$ CRCINA, Inserm, Université d'Angers, F-44000 Nantes; ${ }^{2}$ Paul Papin ICO Cancer Center, \\ CRCINA, Inserm, Université d'Angers, F-44000 Nantes, France
}

Received February 19, 2020; Accepted May 7, 2020

DOI: 10.3892/ijo.2020.5075

\begin{abstract}
Over the past two decades, quantitative proteomics has emerged as an important tool for deciphering the complex molecular events involved in cancers. The number of references involving studies on the cancer metastatic process has doubled since 2010, while the last 5 years have seen the development of novel technologies combining deep proteome coverage capabilities with quantitative consistency and accuracy. To highlight key findings within this huge amount of information, the present review identified a list of tumor invasive biomarkers based on both the literature and data collected on a biocollection of experimental cell lines, tumor models of increasing invasiveness and tumor samples from patients with colorectal or breast cancer. Crossing these different data sources led to 76 proteins of interest out of 1,245 mentioned in the literature. Information on these proteins can potentially be translated into clinical prospects, since they represent potential targets for the development and evaluation of innovative therapies, alone or in combination. Herein, a systematical review of the biology of each of these proteins, including their specific subcellular/extracellular or multiple localizations is presented. Finally, as an important advantage of quantitative proteomics is the ability to provide data on all these molecules simultaneously in cell pellets, body fluids or paraffin-embedded sections of tumors/invaded tissues, the significance of some of their interconnections is discussed.
\end{abstract}

\section{Contents}

1. Introduction

2. Data collection methods

3. Extracellular matrix (ECM)

Correspondence to: Dr Daniel L. Pouliquen, Paul Papin ICO Cancer Center, CRCINA, Inserm UMR 1232, 15 Rue André Boquel, 49055 Angers, France

E-mail: daniel.pouliquen@inserm.fr

Key words: proteomics biomarkers, tumor invasiveness, extracellular matrix remodeling, plasma proteins, membrane proteins, cytoplasmic enzymes, cytoskeletal proteins, endoplasmic reticulum, mitochondrial proteins, nuclear proteins
4. Plasma proteins

5. Membrane proteins

6. Cytoplasm/cytosol

7. Cytoskeleton

8. Endoplasmic reticulum

9. Mitochondrion and nucleus

10. Miscellaneous

11. Extension to and links with other proteins of interest not included in the list

12. Conclusions

\section{Introduction}

The development of molecular characterization of tumors two decades ago led to a revolution in cancer research and therapeutic approaches. In the case of breast cancer, 'molecular portraits' provided by the quantitative analysis of gene expression patterns (1) have helped define different intrinsic subtypes while multiparameter molecular tests such as the PAM-50 provide useful prognostic information (2). However, despite the usefulness of mRNA-based classifications, integrated proteogenomic analyses of breast or colon tumors have revealed that protein abundance cannot be reliably predicted from DNA- or RNA-level measurements as they are only modestly correlated. In particular, proteomics identify colorectal cancer subtypes similar to those detectable by transcriptome profiles, but also reveal features not detectable in transcript profiles, probably as a result of post-transcriptional regulation (3). Further evidence of this unique potential of proteomics-based subtyping was recently provided in the study by Johansson et al who identified protein products mapping to non-coding genomic regions, potentially leading to a new class of tumor-specific immunotherapeutic targets (4).

High-throughput proteomics is still an underdeveloped field compared to transcriptomics (4) and its contribution to oncology has probably not yet been fully realized. However, in two decades, quantitative proteomics has rapidly evolved both technologically (5) and strategically, allowing researchers to explore the complexity of protein interaction networks in a wide variety of situations, but also to formulate new hypotheses to be further functionally tested (6). To identify tumor biomarkers to assist in individualizing treatments for certain types of cancer, many complementary technologies have also been developed (7). As an example, for the majority of the common causes of cancer-related mortality worldwide, such as 
lung cancer, these technologies have led to the identification of predictive biomarkers of drug resistance, candidate biomarkers for diagnosis and prognostic biomarkers (8). To deal with the limited success of 'targeted therapies', quantitative proteomics, together with other major technological and conceptual developments, has reinforced the search for characteristic features of the adhesive-migratory phenotype of malignant cells (9). Some other examples of important contributions include the study of RNA-protein complexes (10), stem cell plasticity (11), chromatin remodeling (12) and more recently, the regulation of mitochondrial function and dynamics (13), shed microvesicles biology (14) or mechanisms of radioresistance (15).

The advent of data-independent acquisition methods (DIA) (16), such as sequential window acquisition of all theoretical mass spectra (SWATH-MS) that combines deep proteome coverage capabilities with quantitative consistency and accuracy (17), has further extended this potential. In particular, SWATH-MS does not rely on precursor intensity for fragmentation selection, but rather analyzes all precursors in specified mass ranges (18). This overcomes the limitations of previous data-dependent acquisition (DDA) methods in mass spectrometry related to the large dynamic concentration range observed in body fluids, and the fact that less abundant proteins were usually masked by highly abundant proteins. With regard to relative quantification, strong correlations have been found between protein abundances and functional activities of a set of drug metabolizing enzymes in human liver microsomes (19). Additionally, although mass spectrometry is not commonly used in clinical laboratories, the validation of cancer biomarkers found by this technology compared with western blot analysis or ELISA has already been established (20).

It was recently demonstrated that proteomes and transcriptomes were better associated in highly proliferative tumors than in lowly proliferative tumors (4). Herein, data on cancer invasiveness are reviewed with the aim of highlighting key findings within the huge amount of information available in the literature. The present review focuses in particular on a list of 76 proteins of interest, selected after crossing with SWATH-MS data collected by our team on experimental models and human tumor samples.

\section{Data collection methods}

The procedure used to identify the list of proteins of interest is summarized in Fig. 1. First, an initial search on the PubMed database was performed on March 7, 2019, with the keywords 'quantitative proteomics', 'cancer' and 'invasiveness'. In total, 93 studies with full text in the English language were analyzed, published between 2005 and 2019. A file of 1,245 proteins mentioned in comparative analyses between tumor cell lines of different invasiveness, tumor cell lines versus normal cell lines, tumors versus normal tissues, invasive or not, from 42 relevant articles was established. The number of citations of each protein in these articles was then recorded, and the 130 potential candidates for which quantitative changes were documented at least in three different studies, were listed for further examination.

Subsequently, this list of 130 candidates was crossed with experimental data collected on rat malignant mesotheliomas (MMs) differing by their invasiveness (21), and then with clinical data from cohorts of patients with colon adenocarcinoma (22) or breast cancer (23). As a result of technological improvements that occurred between these two studies, the number of specific biomarkers identified in breast cancer was higher than that in colon cancer. Although our team is primarily focused on breast cancer, the authors wished to extend the present review to other types of malignant tumors originating in two different tissues in order to validate the most robust and generalizable biomarkers.

This led to a final list of 76 upregulated or downregulated proteins common to the three sources of data, which represent potential tumor invasive biomarkers. The present review is based on i) articles selected from the procedure illustrated in Fig. 1; and ii) the screening of literature for each individual protein listed in Table I with the following keywords 'name of the protein' and 'cancer', without or with 'invasiveness'. Finally, some articles combining two or more of these protein names with these keywords were also analyzed.

\section{Extracellular matrix (ECM)}

A number of the proteins in the list of potential biomarkers of invasiveness are localized in the ECM, either specifically or in parallel to other intracellular localizations, which are summarized in Fig. 2.

S100 proteins. Communications between stromal cells and cancer cells represent a key parameter of invasiveness. The S100 family of proteins in particular is involved in the formation and maintenance of a pro-inflammatory environment. Among the 21 members of this family present in humans, all regulated by $\mathrm{Ca}^{2+}$ binding, 11 are described in the literature in relation to the subject of the present review (S100A4, S100A6, S100A7, S100A8, S100A9, S100A10, S100A11, S100A13, S100A14, S100A16 and S100P). S100A4 and S100A6 are the most extensively documented; however, S100A8, which forms heterodimers with S100A9 [the overexpression of which is very useful for the identification of circulating tumor cells (24)], is also involved in the regulation of inflammatory responses and pre-metastatic niche formation, together with S100A4 $(25,26)$. The heterodimeric protein, named calprotectin, is released by activated granulocytes, and functions in a cytokine-like manner by triggering signaling pathways involved in inflammatory processes. A recent review revealed the complex functionality of this molecule, emphasizing the fact that its function depends on its concentration and location inside or outside the cell (27). Of note, S100A9 and S100A4 exhibit common molecular interactions, including heterodimerization which require levels of $\mathrm{Zn}^{2+}$ that are found in the extracellular space, but not intracellularly (28).

The contribution of S100A4, also known as metastasin, to tumor progression and metastasis in various tumors has been well documented over the past two decades, as recently reviewed (29). In normal and benign lesions, S100A4 is restricted to a few stromal fibroblasts and inflammatory cells (30). By contrast, both tumor cells and stromal cells secrete the protein in malignant tumors $(25,30)$. Moreover, in the context of a pre-metastatic niche (31), the production of S100A4 serves as a link between inflammation and tumor 


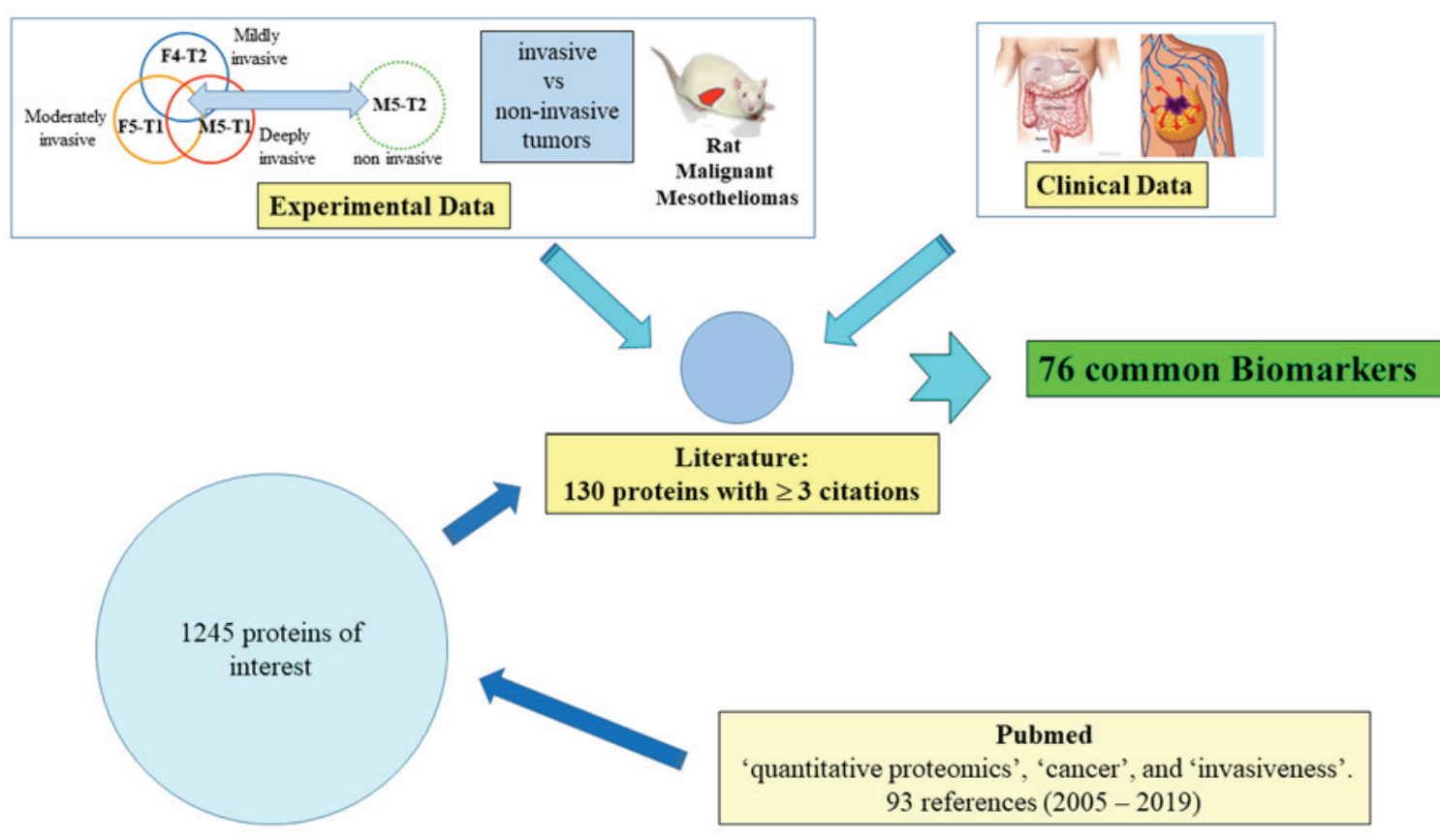

Figure 1. Methodology used for the identification of the 76 main invasiveness biomarkers.

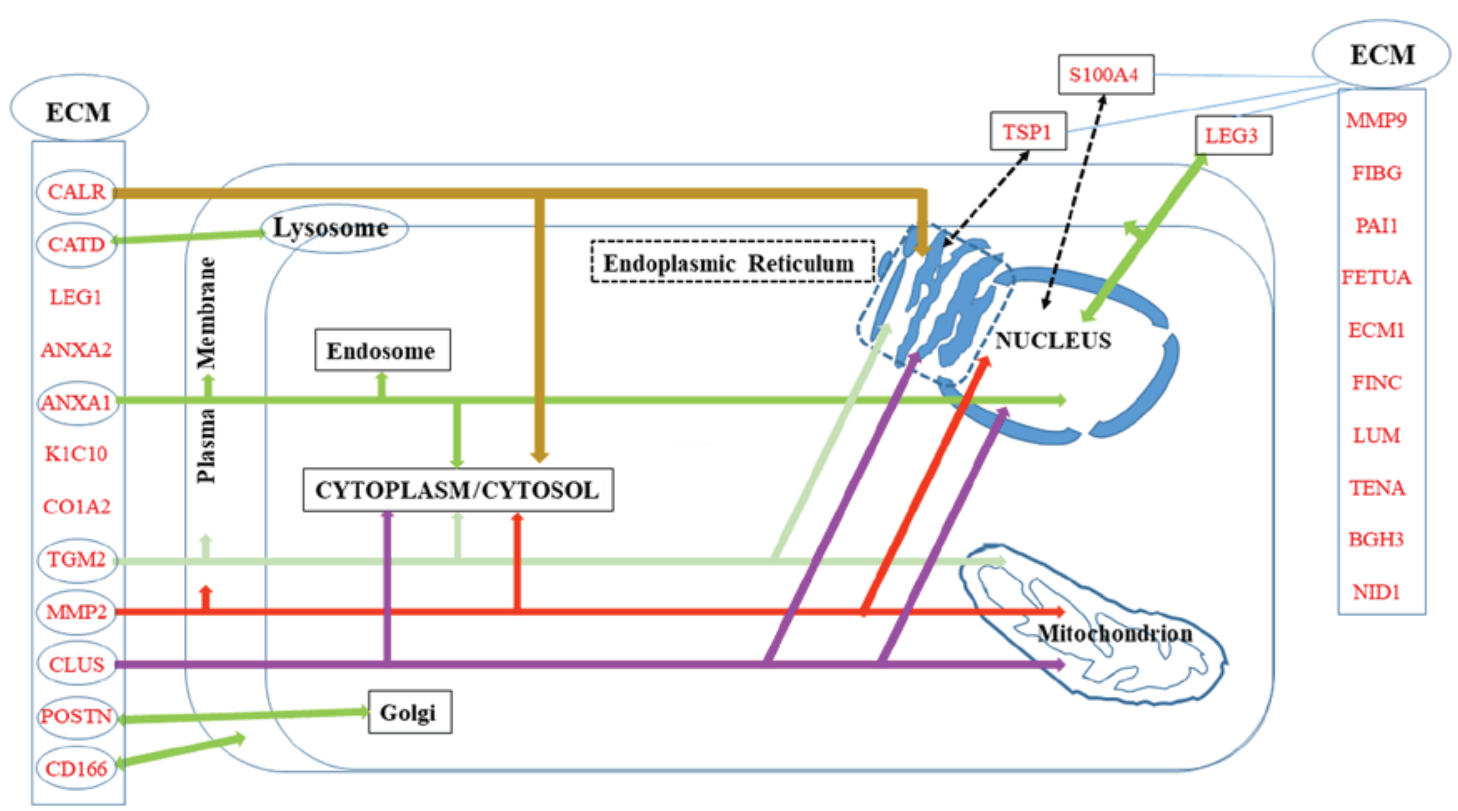

Figure 2. Biomarkers distributed in the extracellular matrix (ECM) and/or other cell compartments.

metastasis and is indicative of a poor prognosis (32). S100A4 is also involved in the epithelial-mesenchymal transition (EMT) and is particularly highly expressed in the peripheral leading edge of breast cancer (26) and non-small cell lung cancer (33). S100A4 is related to tumor characteristics associated with a poor prognosis. The combined gain of S100A4 and the loss of membrane E-cadherin in cervical cancer tend to confirm its link with an unfavorable prognosis (34), in good agreement with previous studies by the authros on experimental malignant mesothelioma $(21,35)$.

S100A6, also known as calcyclin, is overexpressed in the majority of cancers, and its involvement in tumor cell motility has been widely documented (36). In metastatic tumor tissues,
S100A6 expression has also been found to be higher than that in non-metastatic tissues (37). However, the molecular mechanisms underpinning the ability of this protein to regulate cell motility are not yet completely understood, as the down- or upregulation of S100A6 expression has been shown to lead to increased or decreased migration, respectively, in the particular case of osteosarcoma (38). Intracellularly and in vitro, its role in cytoskeletal reorganization and EMT has been widely investigated, although to date, several questions remain unanswered as regards its function/regulation in vivo, such as the confirmation of direct interaction with the cytoskeleton and the determination of the primary cause(s) of its increased expression (36). Finally, S100A6 can be secreted or 
Table I. List of biomarkers of invasiveness identified from quantitative proteomic studies.

\begin{tabular}{|c|c|c|c|c|c|}
\hline Code & Protein name & $\begin{array}{c}\text { PubMed } \\
\text { citations } \\
*\end{array}$ & $\begin{array}{l}\text { Exp. } 1 \\
\text { rat } \\
\text { data \# }\end{array}$ & $\begin{array}{c}\text { Exp. } 2 \\
\text { rat } \\
\text { data } \S\end{array}$ & $\begin{array}{c}\text { Clinical } \\
\text { data } \\
\otimes\end{array}$ \\
\hline $1433 \mathrm{E}$ & 14-3-3 protein epsilon & 3 & & $\square$ & $\mathrm{x}$ \\
\hline $1433 Z$ & 14-3-3 protein zeta/delta & 3 & & $\square$ & $\mathbf{\square}$ \\
\hline ACLY & ATP-citrate synthase & 3 & & $\square$ & $\mathbf{\square}$ \\
\hline ACTN4 & Actinin-4 & 6 & & $\square$ & $\mathrm{x}$ \\
\hline AL1A1 & Retinal dehydrogenase 1 & 6 & & & $\mathrm{x}$ \\
\hline ANXA1 & Annexin A1 & 9 & & $\square$ & $\mathrm{x}$ \\
\hline ANXA2 & Annexin A2 & 6 & $\square$ & & $\mathrm{x}$ \\
\hline ANXA6 & Annexin A6 & 5 & & & घ \\
\hline APMAP & Adipocyte plasma membrane-associated protein & 3 & $\square$ & & $\mathrm{x}$ \\
\hline ATPA & ATP synthase subunit alpha, mitochondrial & 4 & & & घ \\
\hline ATPD & ATP synthase subunit delta, mitochondrial & 4 & & & $\mathrm{x}$ \\
\hline BGH3 & Transforming growth factor-beta-induced protein ig-h3 & 5 & & & - \\
\hline BIP & Endoplasmic reticulum chaperone BIP & 4 & & & $\mathrm{x}$ \\
\hline CADH1 & Cadherin-1 & 4 & & & $\mathrm{x}$ \\
\hline CALR & Calreticulin & 5 & & & $\square$ \\
\hline CALX & Calnexin & 5 & & & $\mathrm{x}$ \\
\hline CATD & Cathepsin D & 9 & & & - \\
\hline CD166 & CD166 antigen & 5 & & & $\mathrm{x}$ \\
\hline CLUS & Clusterin & 6 & & & $\mathrm{x}$ \\
\hline $\mathrm{CO} 1 \mathrm{~A} 2$ & Collagen alpha-2(I) chain & 4 & $\square$ & & घ \\
\hline COF1 & Cofilin-1 & 6 & & $\square$ & घ \\
\hline COIA1 & Collagen alpha-1(XVIII) chain & 4 & & & घ \\
\hline COX5A & Cytochrome $c$ oxidase subunit $5 \mathrm{~A}$, mitochondrial & 4 & & & - \\
\hline DPYL3 & Dihydropyrimidinase-related protein 3 & 4 & $\square$ & & $\mathrm{x}$ \\
\hline ECM1 & Extracellular matrix protein 1 & 5 & & & $\mathrm{x}$ \\
\hline EZRI & Ezrin & 4 & $\square$ & & $\mathbf{\square}$ \\
\hline FAS & Fatty acid synthase & 3 & $\square$ & & घ \\
\hline FETUA & Alpha-2-HS-glycoprotein & 4 & & $\square$ & $\mathrm{x}$ \\
\hline FIBG & Fibrinogen gamma chain & 3 & $\square$ & & a \\
\hline FINC & Fibronectin & 5 & $\square$ & & $\mathbf{\square}$ \\
\hline FLNA & Filamin-A & 5 & & & घ \\
\hline FSCN1 & Fascin & 3 & & $\square$ & $\mathrm{x}$ \\
\hline GELS & Gelsolin & 8 & & & $\mathrm{x}$ \\
\hline GRP75 & Stress-70 protein, mitochondrial & 5 & & & $\mathrm{x}$ \\
\hline GSTP1 & Glutathione-S-transferase P & 8 & & $\square$ & $\mathrm{x}$ \\
\hline $\mathrm{H} 4$ & Histone H4 & 3 & & $\square$ & $\mathrm{x}$ \\
\hline HS90A & Heat shock protein HSP 90 -alpha & 3 & & $\square$ & $\mathrm{x}$ \\
\hline HSPB 1 & Heat shock protein beta-1 & 6 & & $\square$ & घ \\
\hline ITGB1 & Integrin beta 1 & 5 & & $\square$ & $\mathrm{x}$ \\
\hline $\mathrm{K} 1 \mathrm{C} 10$ & Keratin, type I cytoskeletal 10 & 3 & & $\square$ & $\mathrm{x}$ \\
\hline $\mathrm{K} 1 \mathrm{C} 18$ & Keratin, type I cytoskeletal 18 & 4 & & & - \\
\hline $\mathrm{K} 2 \mathrm{C} 8$ & Keratin, type II cytoskeletal 8 & 4 & & $\square$ & $\mathbf{\square}$ \\
\hline KPYM & Pyruvate kinase PKM & 3 & $\square$ & & a \\
\hline LEG1 & Galectin-1 & 6 & & & घ \\
\hline LEG3 & Galectin-3 & 4 & $\square$ & & घ \\
\hline LMNA & Prelamin-A/C & 3 & $\square$ & & $\mathrm{x}$ \\
\hline LUM & Lumican & 4 & & $\square$ & $\mathbf{a}$ \\
\hline MMP2 & $72 \mathrm{kDa}$ type IV collagenase & 6 & & & $\mathrm{x}$ \\
\hline MMP9 & Matrix metalloproteinase-9 & 4 & & & $\mathrm{x}$ \\
\hline MYH9 & Myosin-9 & 3 & $\square$ & & $\mathrm{x}$ \\
\hline
\end{tabular}


Table I. Continued.

\begin{tabular}{|c|c|c|c|c|c|}
\hline Code & Protein name & $\begin{array}{c}\text { PubMed } \\
\text { citations } \\
*\end{array}$ & $\begin{array}{c}\text { Exp. } 1 \\
\text { rat } \\
\text { data \# }\end{array}$ & $\begin{array}{c}\text { Exp. } 2 \\
\text { rat } \\
\text { data } \S\end{array}$ & $\begin{array}{c}\text { Clinical } \\
\text { data } \\
\circ\end{array}$ \\
\hline NID1 & Nidogen-1 & 3 & & $\square$ & $\mathrm{X}$ \\
\hline NPM & Nucleophosmin & 6 & & & $\mathbf{\square}$ \\
\hline PAI1 & Plasminogen activator inhibitor 1 & 6 & & & $\mathrm{x}$ \\
\hline PCNA & Proliferating cell nuclear antigen & 3 & & $\square$ & $\mathrm{x}$ \\
\hline PDIA4 & Protein disulfide-isomerase A4 & 3 & $\square$ & & $\mathbf{\square}$ \\
\hline PDIA6 & Protein disulfide-isomerase A6 & 3 & & $\square$ & घ \\
\hline PHB & Prohibitin & 3 & $\square$ & & $\mathrm{x}$ \\
\hline PHB2 & Prohibitin-2 & 3 & $\square$ & & $\mathbf{\square}$ \\
\hline POSTN & Periostin & 7 & & & $\mathbf{\square}$ \\
\hline PRDX1 & Peroxiredoxin-1 & 6 & & $\square$ & घ \\
\hline PRDX2 & Peroxiredoxin-2 & 3 & $\square$ & & $\mathrm{x}$ \\
\hline PROF1 & Profilin-1 & 6 & $\square$ & & $\mathbf{\square}$ \\
\hline RAN & GTP-binding nuclear protein Ran & 3 & & $\square$ & $\square$ \\
\hline S10A4 & Protein S100-A4 & 3 & $\square$ & & $\mathrm{x}$ \\
\hline S10A6 & Protein S100-A6 & 4 & $\square$ & & घ \\
\hline SERPH & Serpin H1 & 4 & & $\square$ & $\mathbf{\square}$ \\
\hline SSBP & Single-stranded DNA-binding protein, mitochondrial & 3 & & $\square$ & $\mathrm{x}$ \\
\hline STMN1 & Stathmin & 5 & & & $\mathrm{x}$ \\
\hline TAGL & Transgelin & 3 & $\square$ & & घ \\
\hline TENA & Tenascin & 5 & & & $\mathbf{\square}$ \\
\hline TGM2 & Protein-glutamine gamma-glutamyltransferase 2 & 6 & & & घ \\
\hline TPIS & Triosephosphate isomerase & 4 & & $\square$ & घ \\
\hline TPM2 & Tropomyosin beta chain & 4 & & & $\mathrm{x}$ \\
\hline TSP1 & Thombospondin-1 & 7 & & & घ \\
\hline VIME & Vimentin & 8 & & & घ \\
\hline VINC & Vinculin & 4 & & & - \\
\hline
\end{tabular}

*, Common list between the 130 proteins with $\geq 3$ citations (PubMed, keywords: 'quantitative proteomics + cancer + invasiveness'), and experimental rat tumors data (shown below with the \# or $\S$ symbols and in Fig. 1). \#, Shared in common with the 137 proteins listed in supplemental Table S2 in a previous study (21) (common list between each invasive tumors M5-T1, F5-T1 or F4-T2 vs. non-invasive M5-T2). §, Shared in common with the list of 457 proteins exhibiting significant changes $(\mathrm{P}<0.05$, Marker View statistical test), two most invasive tumors (M5-T1 and F5-T1) vs. non-invasive (M5-T2) (21). ०, Shared in common with the list of proteins exhibiting significant changes $(\mathrm{P}<0.05)$ from two clinical studies on patients with colorectal adenocarcinoma ( $\square$ ) (22), or breast cancer (x) (23), or from both cohorts (घ).

released by some cell types and the observation that serum levels are elevated in patients with gastric cancer, which is associated with lymph node metastasis (39), raises the question of the extracellular effects of this protein (36).

Annexins and galectins. Although functionally unrelated, these two families of proteins for which extracellular localization has been well documented, both share evidence of secretion via direct translocation and using a vesicle-based pathway, instead of the conventional endoplasmic reticulum/Golgi network in the context of cancer (40).

Annexins. Annexins are all $\mathrm{Ca}^{2+}$-regulated, phospholipid binding proteins involved in membrane domain organization and membrane trafficking (41); however, they have functionally distinct roles inside and outside cells. Annexin A6 is the largest member of the family, containing two annexin domains connected by a linker, and is distributed differently from Annexins A1 and A2 (42). Annexin A6 was initially demonstrated to be mainly located at the plasma membrane and endosomal compartment, although an increasing number of studies have presented evidence for its extracellular role in cell migration (43). Similar to Annexin A2, Annexin A6 is secreted via the exosomal pathway, and is predominantly cell surface-associated in invasive breast cancer cells (44). Keklikoglou et al recently demonstrated that extracellular vesicles enriched in Annexin A6 were released by mouse mammary cancer cells when treated with chemotherapy to facilitate the establishment of lung metastasis (45). Annexin A6 stabilizes activated EGFR on the cell surface for persistent downstream signaling (46). Nevertheless, Annexin A6 expression resumed in these invasive cancer cells following prolonged treatment with tyrosine kinase inhibitors, in relation to the recycling 
of two integrin receptors of fibronectin, and to accumulation of cholesterol in late endosomes $(47,48)$. In humans, the contribution of Annexin A6 to increased pancreatic ductal adenocarcinoma has also been reported to depend on tumor cell-mediated uptake of an ANXA6/LRP1/TSP1 complex produced by cancer-associated fibroblasts (CAFs) (49). Finally, apart from reorganization of membrane lipids, Annexin A6 also forms reversible, membrane-cytoskeleton complexes through interactions with actin and $\alpha$-actinin, and facilitates localized recruitment of signaling proteins by binding to a number of them (43). In particular, a recent study documented its role as a scaffold for Ras proteins (50).

Although Annexins A1, A2 and A6 are all present in endosomal compartments, the extracellular functions of Annexins A1 and A2 differ in several respects: Annexin A1 is involved in the regulation of inflammation, apoptosis, leukocyte trafficking and inhibition of neutrophil and monocyte extravasation (51), while Annexin A2 is a co-receptor for tissue plasminogen and participates in neoangiogenesis (41). Early studies have demonstrated that Annexin A1 regulates leukocyte migratory events through its function as an agonist of $n$-formylpeptide receptors (FPRs), initiating a cascade of signaling events (52). Further investigations have indicated that the binding of Annexin A1 may lead to both pro- and anti-inflammatory effects depending on the type of ligand, its expression being either increased or decreased in different types of cancers(53). In the particular case of mammary tumorigenesis, studies have revealed that the expression and functional roles of Annexin A1 are controversial $(54,55)$, suggesting an association which may be much more complex than initially thought (56). This is probably due to its diverse actions on the many cell types of the tumor and also to the great complexity of the network of ANXA1-regulated proteins (54). The contribution of hypoxia to the combined upregulation of this protein and S100A4 has recently been described (57). In addition, a link between MMP9 and these two proteins has been reported (58), mirroring previous findings (59).

Annexin A2 is a multifunctional protein found at various cellular locations. In addition to being present in soluble form in the cytoplasm or associated with the actin cytoskeleton, and both the intra- and extracellular sides of the plasma membrane, this crucial protein is subjected to complex regulation via ligand binding and post-translational modifications (60). Although it is overexpressed in numerous types of cancer, both its upregulation and downregulation have been suggested as prognostic biomarkers (61). The overexpression of Annexin A2 in glioblastoma is associated with tumor aggressiveness and patient survival, and with a mesenchymal phenotype (62). These observations are coherent with the involvement of EMT in ovarian and colorectal cancer invasiveness $(63,64)$. The role of EMT in pancreatic cancer has also been reported to depend on the combined expression of tenascin C and Annexin A2 (65). Other studies in the same field have described links between Annexin A2 expression and S100A4 or S100A6 as prognostic biomarkers for invasive types of urothelial carcinoma (66) or gastric cancer (67). For invasive breast cancers characterized by increased glycolysis and carbonyl stress, the production of advanced glycation end products (AGEs) and AGE-modified proteins leads to alterations, affecting several proteins in parallel to the increase in
Annexin A2, including fibrinogen gamma chain and prohibitin present in the list of biomarkers in the present review (68). Notably, a proteomic analysis of pleural effusion from lung adenocarcinoma patients identified seven proteins not previously reported in plasma, including Annexin A2, as well as another protein from our list, BGH3 (69). Finally, an investigation of the interaction of ovarian cancer and peritoneal cells identified several ECM proteins including Annexin A2, and highlighted links with $\mathrm{BGH} 3, \mathrm{PAI} 1$, fibronectin and periostin (70).

Galectins. Since the pioneering work dedicated to the comparative expression of galectins 1 and 3 in advanced cancers (71), revealing in particular their contribution to the stimulation of glioblastoma cell migration (72), interest in these proteins has continued to grow over the past two decades.

Galectin 1 belongs to the first group of this family, characterized by the presence of one conserved carbohydrate-recognition domain (CRD). It represents an interesting target for the development of cancer therapies (73). Previous studies have confirmed the pioneering discovery that galectin 1 overexpression is involved in cancer invasiveness. By 2016, the role of galectin 1 in cancer progression had been clearly demonstrated, although the mechanisms underlying its different actions were not well understood (74). To overcome this gap in knowledge, numerous studies have been conducted over the past few years. For example, Bhat et al described the role of nuclear localization, suggesting that differential glycosylation at the level of tissue microanatomy regulates this parameter in breast carcinoma (75). Shen et al demonstrated the mechanisms through which galectin 1 mediates the activity of matrix metalloproteinase (MMP) 9 through the Ras-Rac1-MEKK4-JNK-AP1 signaling pathway in urinary bladder urothelial carcinoma cell invasion (76). In addition, the mechanisms through which galectin 1 induces EMT have been investigated in detail, including its secretion by cancer-associated fibroblasts and its binding to integrin $\beta 1$ (ITGB1) (77) or the non-canonical hedgehog pathway (78) in gastric cancer, and the activation of an $\alpha v \beta 3$-integrin/FAK/PI3K/AKT signaling pathway in hepatocellular carcinoma (79). Finally, additional findings by Qian et al revealed that galectin 1 induces the secretion of stromal cell-derived factor-1, thus modulating stromal pancreatic stellate cells in the context of pancreatic cancer metastasis (80), and plays an important role in immune escape of gingival squamous cell carcinoma through induction of $\mathrm{T}$ cell apoptosis (81).

However, galectin 3 has incited twice as much interest as galectin 1 in the context of cancer invasiveness, and a seven-fold increase was observed in the number of PubMed references on galectin 3 between the years 1999 and 2014. The wealth of data collected during this period has led to several reviews of excellent quality. Galectin 3 expression is closely involved in tumor cell transformation, migration, invasion and metastasis in a wide variety of cancers (82). The value of this protein as a prognostic biomarker for gastric cancer was confirmed in 2018 by the observation that its overexpression is associated with shorter overall survival in all patients (83). Galectin 3 orchestrates different cell events in the tumor microenvironment, suppressing immune surveillance by killing $\mathrm{T}$ cells and interfering with NK cell function (84). Upon secretion, galectin 3 can oligomerize, playing a homeostatic role in tumors by 
favoring either the exit of tumor cells from a stressed environment or the entry of endothelial and immune cells into the tumor organoid (85). Finally, two other biomarkers involved in cell-matrix interactions and present in the list of invasive biomarkers in the present review, fibronectin and S100A4, were found together with galectin 1 and galectin 3 , in a list of 61 statistically significant differentially expressed genes associated with $E R B B 2$ overexpression in breast cancers, and their clinical relevance was demonstrated at the protein level (86).

Cathepsin D and transglutaminase 2 (TGM2). Another type of secreted protein affecting both cancer cells and stromal cells is cathepsin D (CATD), a lysosomal cysteine and aspartic proteinase, which is generally overexpressed in aggressive cancers and is associated with a poor prognosis (87). In the case of breast cancer, Derocq et al demonstrated that CATD secreted in the extracellular environment triggers fibroblast outgrowth by binding to the $\beta$-chain of the LDL receptor-related protein-1 (LRP1), a scavenger receptor mediating the endocytosis of various extracellular ligands and involved in signal transduction and gene transcription (88). The multiple roles of CATD show increasing promise for the development of novel anticancer agents (89).

The ubiquitous TGM2 belongs to a family of enzymes that catalyze the formation of covalent bonds between a free $\varepsilon$-amino group of a lysine and the $\gamma$-carboxyl group of a glutamine. Although localized in different cellular compartments, it can also be exported from the cell, then interacting with and/or cross-linking numerous components of the ECM where together with nuclear factor $(\mathrm{NF})-\kappa \mathrm{B}$ it influences cellular sensitivity to genotoxic agents and activates EMT (90). TGM2 is overexpressed in various types of cancer, where it remodels and stabilizes the ECM in association with MMP2 and MMP9, and high levels of TGM2 are associated with lower survival rates (91).

Collagen type I and gelatinases. Among the 28 types of collagens that represent the most abundant proteins of the extracellular matrix, two are present in our list of invasive biomarkers, both of which assemble into higher-order supramolecular structures such as fibrils (92). Almost ten years ago, Garamszegi et al reported that collagen type I, among other ECM molecules, induces Smad2 activation in human breast cancer cells, suggesting that cell-matrix communication was more complex than previously thought (93). The interest for this molecule has grown during over the past decade through the discovery that this major fibrillary component of the stroma induces the dedifferentiation of epithelial cells and the disruption of the E-cadherin adhesion complex (94). In parallel, the overexpression of this type of collagen has been shown to be associated with tumor development in gastric cancer (95) and medulloblastoma (96). Subsequently, a detailed proteomic analysis of breast tissue collagens has confirmed that fibrillary collagens, in particular, are increased in tumor tissue compared to matched normal tissue, in agreement with findings by other authors (97). A link with the presence of bone marrow-derived fibrocyte-like cells, defined as $\alpha-1$ type I collagen-positive cells producing FGF2, has also been reported in human malignant mesothelioma (98). More recently, Rong et al demonstrated that the collagen type I alpha 2 chain (COL1A2) gene modulated cell motility through interaction with the cytoskeleton (99).

Cancer cells share with immune cells the ability to penetrate the dense network of the BM. To cross this barrier, they secrete different categories of proteases, in particular MMPs (also known as matrixins) (92), among which MMP2 and MMP9 (gelatinases a and b, respectively) expression has been shown to be associated with invasiveness (100). MMP9 has the particularity of degrading both type I and type IV collagens, and for this reason it facilitates invasion across the BM (101) in association with Annexin A1 (59), resulting in a poor prognosis (102). The association of both MMP9 and MMP2 with tumor invasiveness was further confirmed for a number of cancer types (103). A link with S100A4 was soon established in the context of breast cancer invasiveness (104). These investigations demonstrated that exposure to interleukin (IL) $-1 \beta$ induced EMT in MCF-7 cells, which could then respond to chemokine CXCL12 (101), ultimately leading to the expression of S100A4 and increased secretion of MMP2 and MMP9 (105). Matsuura et al contributed further insight into the mechanistic process by demonstrating that S100A4 binds to Smad3, an important mediator of transforming growth factor (TGF)- $\beta$ signaling, in a $\mathrm{Ca}^{2+}$-dependent manner, which ultimately induces MMP9 expression (106).

Fibronectins. Fibronectin is a major stromal protein associated with tumors. It is a part of the four matrix components that are common to breast cancer progression and mammary gland involution (107). Its contribution to the mechanisms through which a tumor cell undergoes metastasis to a predetermined location was initially documented by Kaplan et al in 2005, who demonstrated that bone marrow-derived hematopoietic progenitors that express the vascular endothelial growth factor receptor 1 (VEGFR1) form cellular clusters that upregulate fibronectin, providing a niche for incoming tumor cells (108). Other factors have been identified more recently, including a platelet ADP receptor that recruits $\mathrm{VEGFR} 1^{+}$cells in the lung, fibroblasts that secrete both fibronectin and S100A4, or exosomes produced by pancreatic ductal adenocarcinoma cells and taken up by Kupffer cells, leading to upregulation of fibronectin production by hepatic stellate cells (31). Another advancement in the understanding of the metastatic process was the discovery that several ECM proteins, including fibronectin are processed via the plasminogen-plasmin pathway as a result of interactions between ovarian cancer cells and peritoneal cells (70). Interactions between fibronectin and integrins, in particular $\alpha 5 \beta 1$, could provide interesting prospects for the treatment of stroma-rich tumors. Studies on the parameters that regulate such interactions have highlighted the modulating role played by tenascin C (109). Finally, fibronectin plays other important roles, revealed by silencing its gene which leads to the inhibition of cell proliferation and the promotion of cell senescence and apoptosis via the regulation of the PI3K/AKT signaling pathway (110).

Proteoglycans. Proteoglycans, which consist of a core protein and glycosaminoglycan side-chains, are a large family of proteins involved in interactions of cells with the ECM. Two of these, ECM1 and LUM, appear in the list of invasive biomarkers in the present review. 
Extracellular matrix protein 1 (ECM1) is significantly elevated in a number of epithelial tumors, giving rise to metastases, and its high expression around blood vessels has been suggested to play a role in angiogenesis (111). Interest for this protein grew significantly after a 2008 study classifying tumors on the basis of the expression of ECM components in relation to different clinical outcomes (112). Subsequently, Lal et al established this protein as a novel prognostic biomarker for poor long-term survival in 134 women diagnosed with invasive breast cancer (113), and the link with EMT was documented by two independent studies on breast cancer and hepatocellular carcinoma $(114,115)$. The silencing of ECM1 in two triple-negative breast cancer cell lines has revealed that it regulates actin cytoskeletal architecture and decreases the expression of the prometastatic protein S100A4, suggesting that it is the primary effector of the changes observed in morphology, migration, invasion and adhesion (116). Finally, ECM1 facilitates the expression of genes associated with EMT by activating the ITGB4/FAK/glycogen synthase kinase $3 \beta$ signaling pathway (117).

In contrast to ECM1, lumican (LUM) initially exhibited antitumor activity $(118,119)$. However, in 2012 , Radwanska $e t$ al revealed that the role of lumican in cancer cell motility was more complex than previously considered, through the involvement of gelsolin, a protein with multiple effects on the cellular pool of actin (120). The role of lumican in cancer appears to vary according to the type of tumor, with a restrictive role in prostate cancer invasion (121) and a role in colorectal adenoma-to-carcinoma progression (122). Its complex role has been investigated in detail in several studies, revealing in particular that glioblastoma and neuroblastoma cancer stem-like cells promote the activation of large quantities of lumican and decorin in the context of temozolomide resistance (123), while lumican deficiency promotes a pro-angiogenic tumor phenotype in melanoma (124).

Matricellular proteins. In addition to the galectins discussed above, two other proteins belonging to this category are present in the list of invasive biomarkers in the present review, periostin and thrombospondin-1 (TSP1), both of which have been reported to represent secreted matrix molecules decorating ECM fibers in the process of tissue-specific restricted guidance of cancer invasion (125).

Periostin (also known as POST) interacts with multiple cell-surface receptors, particularly integrins, promoting cancer cell survival, EMT, invasion and metastasis (126). In a large cohort of 300 patients with breast cancer, Kim et al demonstrated that a high epithelial periostin expression was more frequently observed in the distant metastatic relapse-positive group, compared with the negative group and was associated with a reduced overall survival (127). In relation to its ability to induce EMT, Mino et al reported that periostin expression was markedly higher in an undifferentiated intrahepatic cholangiocarcinoma cell line compared with a moderately differentiated one (128).

Similar contradictory findings were initially reported for TSP1 in relation to cancer progression, as this protein presents both stimulatory and inhibitory effects (129). An immunohistochemistry study of 80 cases of intraductal papillary-mucinous neoplasms of the pancreas revealed an association between
TSP1 and tumor invasiveness: Patients in the strongly positive group exhibited a significantly poorer prognosis compared with the negative group (130). Of note, Firlej et al described the capacity of TSP1 to increase both hypoxia and cell migration which appear to be linked (131). In another type of cancer for which hypoxia is a hallmark, the increased aggressiveness of pancreatic ductal adenocarcinoma is dependent on the formation of Annexin A6/LDL receptor-related protein 1/TSP1 complexes by cancer-associated fibroblasts (CAFs) and their uptake by tumor cells (49). Platelet-secreted TSP1 contributes to colon cancer invasiveness by promoting the signal regulation of MMP-9 via the p38MAPK pathway (132). Finally, Joshi et al investigated the mechanisms through which bone marrow-derived mesenchymal stromal cells and prostate cancer cells interact, demonstrating that the bioactive principle responsible for this chemotaxis in co-culture was present in a high-molecular weight fraction containing TSP1, and the formation of complexes of this protein with fragments of fibronectin function as matrikines (133).

TGF- $\beta$-induced protein ig- $h 3$. BGH3 (TGFBI, also known as $\beta$ ig-h3) is involved in cell-collagen interactions by binding to types I, II and IV collagen. It has been described as a promoter or a suppressor of cancer growth as its effect is apparently highly cell type-dependent. BGH3 is upregulated in a number of tumor types, and Lebdai et al demonstrated that this overexpression in aggressive clear cell renal cell carcinoma was associated with the stage, size, grade and necrosis (SSIGN) score, as well as with outcomes (134). In melanoma, Nummela et al also reported that BGH3 impaired the adhesion of melanoma cells to collagen type I, fibronectin and laminin, thus confirming its role as an important regulator of invasive growth (135). Additionally, Klamer et al revealed that the upregulation of $\mathrm{BGH} 3$ in hematopoietic stem and progenitor cells may help loosen the adhesive contacts with the bone marrow niche from which they originate, thus making them susceptible for polarization and subsequent egress (136). Finally, quantitative changes in BGH3 were also related to the parallel evolution of other ECM proteins associated with invasiveness, such as fibronectin, periostin and Annexin A2 (70), enzymes involved in redox regulation of the cell, such as peroxiredoxins (137), or S100A4 in the context of EMT (138).

CD166 antigen. CD166 [also known as activated leukocyte cell adhesion molecule (ALCAM)], is a member of the immunoglobulin superfamily. It was first described as a novel actor in invasive growth and control of matrix metalloproteinase activity (139). A first review of its interest in cancer highlighted the existence of a marked heterogeneity of expression in different tumors, with two additional levels of complexity due to the fact that its expression is dependent on the stage of tumor development and on RNA and protein levels in breast cancer tissues (140). Weidle et al subsequently confirmed and detailed the context-dependent prognostic impact of CD166 expression in cancers (141). The recent finding by von Lersner et al that CD166 promotes malignant behavior through the regulation of its availability (dynamic turnover of the protein at the cell surface) rather than its specific activity, provides a key explanation of its heterogeneous expression within malignant diseases (142). 


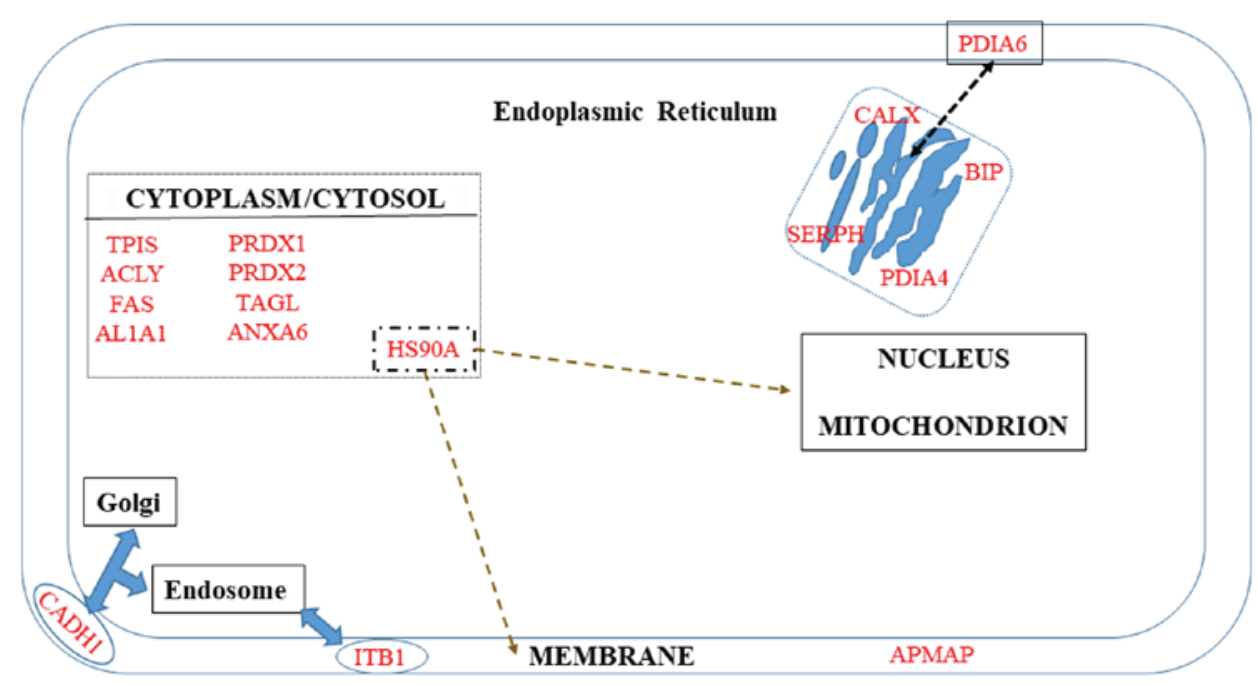

Figure 3. Biomarkers distributed in the cell membrane, cytosol and endoplasmic reticulum (ER).

Nidogen-1 (NID1). Basement membranes (BMs) consist mainly of collagen type IV, laminins and glycoproteins, including nidogens and heparin sulfate proteoglycans (143). The main component of nidogens, NID1, binds to laminin and acts as a bridge to the collagen network to complete the core basement membrane scaffold (144). However, in studies on the matrisome, which includes not only the structural components of the BM, but also proteins that it interacts with, or modifies, the ECM, NID1was additionally found to be expressed by the stroma (145). Among the numerous studies documenting the implication of NID1 in cancers, Zhou et al demonstrated that the expression of NID1 in ovarian cancer cells revealed an EMT phenotype characterized by the enhancement of mobility, invasiveness and cisplatin resistance (146), while Pedrola et al observed a significant increase in NID1 expression in the invasion front of endometrial tumors compared to their paired superficial zone (147).

\section{Plasma proteins}

Plasminogen activator inhibitor 1 (PAI1). PAI1 is a glycoprotein synthesized by various normal cells and a large number of different tumor cells. It belongs to the serine protease inhibitor super family (SERPIN), which probably represents the most important component of the plasminogen activator system (148). A high tumor level of this protein has been associated with a poor patient prognosis (149). This association was confirmed in renal cell carcinoma (150) and breast cancer; higher concentrations of PAIl have been shown to be associated with an aggressive phenotype and a poor prognosis, with a positive correlation has been found with MMP9 (151). Rhone et al further analyzed the clinicopathological determinants of patients with invasive breast cancer and found significantly higher PAI1 concentrations in patients with ductal carcinoma compared to those with lobular carcinoma, suggesting that a high PAI1 expression predisposes to a pro-coagulant environment expressed by simultaneous activation of coagulation and fibrinolysis suppression (152). Finally, PAI1 is now considered to be a prognostic factor, particularly in breast cancer, and $\mathrm{Li}$ et al recently reviewed the numerous tumor promoting factors involved in the modulation of PAI1 activity (153).

Alpha-2-HS-glycoprotein. Alpha-2-HS-glycoprotein [also known as fetuin-A (FETUA)] is a serum glycoprotein involved in the adhesion of tumor cells, functioning as a chemoattractant in breast cancer progression (154), and interacting synergistically with CXCL12 at low concentrations (155). FETUA is endocytosed by tumor cells, enhancing the secretion of exosomes to the extracellular milieu that ultimately promotes cell spreading and adhesion, a process that also requires Annexin A2 and A6 $(44,46,50,156)$. Combined with ECM1, the diagnostic potential of this protein has recently been confirmed in another cancer type, non-small cell lung cancer (157).

Fibrinogen gamma chain (FGG). Interest for this protein in cancer emerged through the discovery of its presence in a list of seven molecules associated with the formation of AGEs in tumors exhibiting increased glycolysis and carbonyl stress (68). Together with other downstream thrombin procoagulant targets, fibrinogen has long been investigated as a promoter of tumor cell metastatic potential, which was confirmed through the experimental demonstration that tumor growth was markedly impeded in fibrinogen-deficient mice (158). Additional evidence was provided by Honda et al, who found a protein complex containing FGG in plasma from patients with advanced ovarian cancer (159), and by the report of its association with gastric cancer (160). Finally, in a study investigating the clinicopathological significance of this protein in the process of migration and invasion of hepatocellular carcinoma cells, a higher FGG expression was significantly associated with a higher recurrence rate and a shorter survival through EMT signaling by regulating the expression levels of Slug and zinc finger E-box-binding homeobox 1 (ZEB1) (161).

\section{Membrane proteins}

A number of proteins are known to be localized in the membrane but are not restricted to it (Fig. 3). The first category 
includes ITB1 and APMAP. The second category, which corresponds to proteins additionally localized in Golgi and endosomes (CADH1), ER (PDIA6), or cytoplasm (HS90A), will be discussed in the third paragraph of this chapter.

ITGB1. More than 10 molecules are known to bind to the cytoplasmic tail of this protein, some of them acting as binding platforms for cytoskeletal and signaling molecules; however, the mechanisms through which integrin signaling is induced in the intracellular space have not yet been elucidated (162). To date, the associations between ITGB1 and the clinical features of patients with cancer are still unclear and a number of studies have reported contradictory conclusions depending on the type of cancer $(163,164)$.

Adipocyte plasma membrane-associated protein (APMAP). Recently, APMAP, discovered in 2001 (165) during investigations on the course of adipocyte differentiation, was found to interact with two extracellular collagen cross-linking matrix proteins, lysyl oxidase-like 1 and 3, suggesting that it may represent a novel regulator of extracellular matrix components (166). A crucial step was the discovery that this protein was increased in sera from a large cohort of patients with prostate cancer compared to a control group (167). A few months ago, these investigations finally led Jiang et al to reveal a novel crucial functional role of cholesterol, which was shown to induce EMT in prostate cancer metastasis through the accumulation of APMAP in cholesterol-induced lipid rafts (168).

Membrane proteins with multiple localizations. The keystone position of S100A4 in the acquisition of invasiveness by cancer cells can be illustrated by its inverse correlation with E-cadherin expression in different invasive phenotypes of oral squamous cell carcinoma (169). In melanoma cells, this inhibition of E-cadherin expression, which leads to EMT and increased invasiveness, has been shown to be associated with the upregulation of Annexin A1, which can be reversed by the use of small interfering RNAs (170). Overall, E-cadherin functional loss has been associated with a poor prognosis and survival in various types of cancer (171). Notably, Yu et al recently reported an inverse correlation between E-cadherin and peroxiredoxin 1 expression, and demonstrated that these two combined parameters were associated with EMT, poor differentiation, deeper invasion and an advanced TNM stage of gastric cancer (172).

\section{Cytoplasm/cytosol}

Potential biomarkers of invasiveness present in the cytosol/cytoplasm are summarized in Fig. 3.

Metabolic enzymes. Glycolysis dysregulation is a main hallmark of cancer cells and has been the subject of extensive investigations (173) since the research by Warburg a century ago (174). These studies have emphasized the key role of enzymes in the adaptation to hypoxia, including triose phosphate isomerase (TPI) which catalyzes the interconversion of dihydroxyacetone phosphate and glyceraldehyde-3-phosphate, playing an important role in the development of many types of cancers (175). Apart from its metabolic function, Lincet and Icard demonstrated that this enzyme also participated in cell cycle activation (176), while its transcriptional regulation involves microRNAs (miRNAs/miRs)-22/28 (177).

A growing interest in fatty acid synthase (FAS) emerged in oncology in the mid-2000s, when this lipogenic enzyme was found to confer growth and survival advantages to cancer cells rather than functioning as an anabolic energy-storage pathway (178). FAS upregulation has been shown to be associated with a poor prognosis in a variety of cancers, although the underlying mechanisms are yet not completely understood. Its localization in the nucleus in a subset of prostate cancer cells has been found to be associated with the Gleason grade (179). Subsequently, Wang et al revealed that the knockdown of this enzyme in human colorectal cancer cell lines attenuated the activation of the Wnt signaling pathway and metastasis; a positive correlation was observed in patients between FAS expression and Wnt signal biomarker gene expression (180). These investigations opened up interesting therapeutic prospects against prostate (181) and breast cancer cells (182).

Another key enzyme involved in the biosynthesis of fatty acids is ATP-citrate lyase (ACLY), which is upregulated or activated in several types of cancer (183), particularly in gastric cancer, where its regulation involves miR-133b (184). These observations have led to the development of ACLY inhibitors attracting interest as promising anticancer agents (185), with citrate levels monitored as an indicator of cancer aggressiveness and/or as a biomarker for response to therapy (186).

Peroxiredoxins. A number of cancer cells are characterized by an increase in reactive oxygen species (ROS) and a dysregulation of enzymes involved in the redox-regulating proteins, in particular peroxiredoxins, which catalyze the peroxide reduction of $\mathrm{H}_{2} \mathrm{O}_{2}$, organic hydroperoxides and peroxynitrite (187). The over-simplification of the role of 'antioxidants', which until now was attributed to these enzymes has recently been questioned (188), as the genetic disruption of their expression in mice has been shown to lead to an increased incidence of neoplasia, consistent with a probable role in the protection of genomic integrity (189). Moreover, although their overexpression has been mostly reported in various malignant tumors, the suppression of 2-Cys peroxiredoxins has also been found in certain metastatic cancers (190), raising questions as to their complex functions related to tumor cell invasiveness, with important implications for therapies (191). In the particular case of peroxiredoxin 1, a major member of the family present mainly in the cytosol, the recent study by Kim et al demonstrated that this protein has RNA-binding properties, binding to a specific subset of small nucleolar RNAs (snoRNAs) and regulating these molecules at the post-transcriptional level (192).

Pyruvate kinase PKM. PKM, which catalyzes the final step in glycolysis, consists of four isoforms in mammals, two of which, PKM1 and PKM2, are encoded by the PKM gene through alternative splicing of mutually exclusive exons (193). Although PKM2. but not PKM1 was initially considered to favor cancer cell proliferation, the exclusive role of PKM2 in tumorigenesis has recently been challenged. In the particular case of liver tumorigenesis, various PKM1/PKM2 ratios and pyruvate kinase activities can sustain the glucose catabolism 


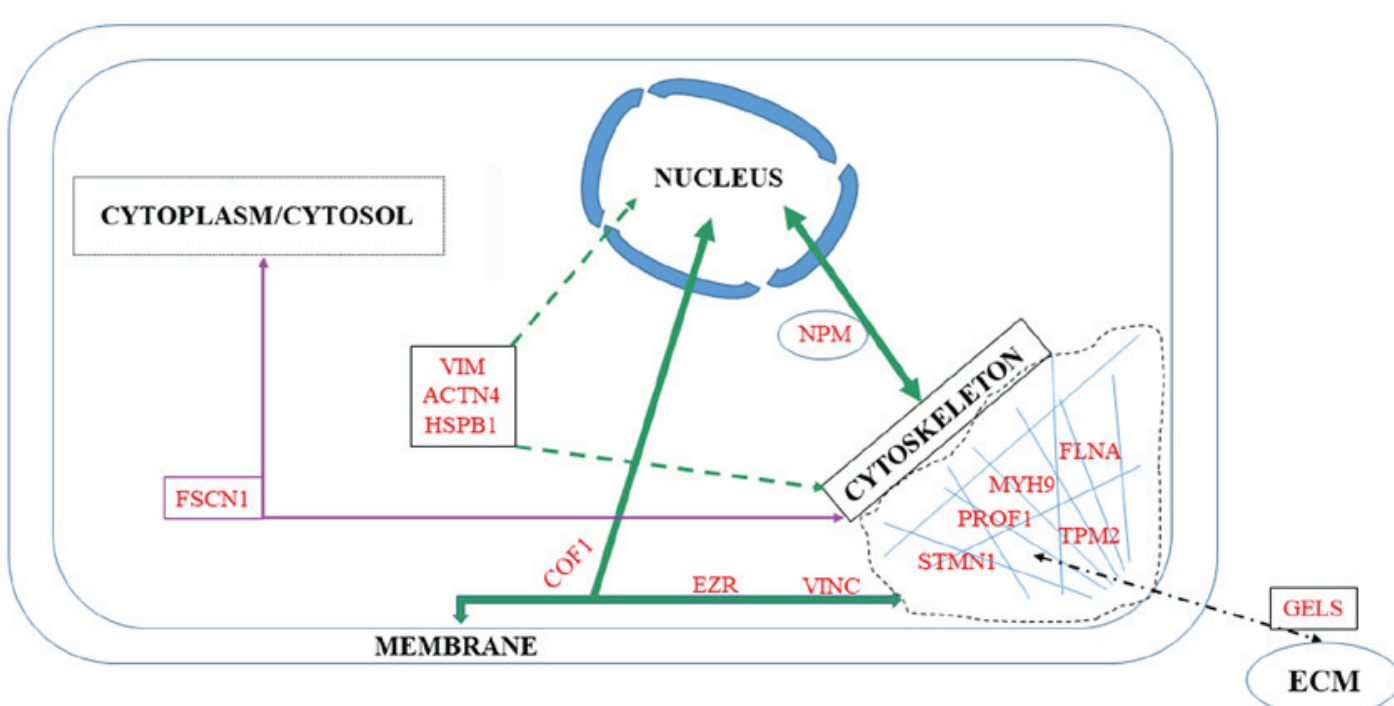

Figure 4. Cytoskeletal biomarkers and their associations with other cell compartments.

required for the process (194). Moreover, although PKM2 has been suggested to be the predominant isoform in cancer cells, providing a basis for the development of novel therapeutic strategies (195), mass spectrometry-based proteomic analyses have demonstrated that PKM2 can be detected in both cancer and normal cells (196). Nevertheless, deeper investigations evaluating the mechanisms through which the two isoforms regulate the invasiveness of pancreatic ductal adenocarcinoma have revealed that both regulate cell migration and invasion in vitro, but only PKM2 overexpression the promotes metastasis of cancer cells in vivo (197).

Aldehyde dehydrogenases. This superfamily consists of 19 proteins displaying mainly catalytic functions involved in detoxification, and their role in cancer has been widely emphasized over the past decade (198), particularly in relation to stem cells and resistance to chemotherapy (199). The overexpression of the first member of this family, ALDH1A1, also known as retinal dehydrogenase 1 , is generally associated with poor outcomes (200-202).

\section{Cytoskeleton}

Among the 76 upregulated or downregulated proteins in the list of potential tumor invasive biomarkers in the present review, seven belong to the cytoskeleton, while another seven interact with the membrane or the nucleus (Fig. 4).

Cytoskeletal proteins. Transgelin is a protein which affects the dynamics of the actin cytoskeleton through the stabilization of actin filaments. This biomarker is involved in a number of cancer-related processes and was initially described as a tumor suppressor. The transgelin level has been shown to be decreased in tumor cells relative to cells of healthy tissues. However, it can be highly expressed by the reactive tumor stroma and its re-expression in tumor cells in the more advanced stages of cancer can support migration and metastasis (203). In support of this observation, transgelin positivity has been associated with more aggressive tumors, a high $\mathrm{Ki}-67$ index and low estrogen and progesterone receptor expression levels in of breast cancer (204).

Fascin is another protein regulating cytoskeletal structures which coordinates motility and invasion and promotes filopodia formation in carcinoma cells. Although absent from most normal epithelia, its expression has been associated with metastasis in colorectal and gastric cancers (205).

Stathmin is a major microtubule-destabilizing protein which promotes microtubule depolymerization and mediates the effects of $\mathrm{p} 27^{\mathrm{Kipl}}$, an inhibitor of cyclin-dependent kinase complexes (206). This action is obtained either through the sequestration of free tubulin dimers or directly by the induction of the microtubule-catastrophe. Thus, stathmin is an important target of the main regulator of the $\mathrm{M}$ phase and offers interesting prospects for anti-metastatic therapies (207). The value of stathmin as a prognostic biomarker has been confirmed by the observation that its overexpression is associated with tumor cell differentiation, lymph node invasion and a high TNM stage (208).

Profilin-1 (PROF1) is an actin-monomer binding protein ubiquitously expressed in all cell types. It regulates actin dynamics and cell motility and plays an important role in the migration of cancer cells (209). In addition to its sequestering function on actin monomers, PROF1 promotes the assembly of globular-actin monomers (G-actin) into filamentous-actin (F-actin) (210), interacts with certain membrane lipids, and is also involved in regulating the expression of several cancer stem cell genes (211). PROF1 has been shown to be downregulated in different types of cancer, including breast, pancreatic and hepatocellular carcinoma, and it is associated with aggressive clinicopathological characteristics and a poor prognosis (212).

Filamin A (FLNA) was the first actin filament cross-linking protein identified in non-muscle cells and the contribution of its structure and functions to cell migration and adhesion has already been reviewed (213). Differences in subcellular localizations and effects on cancer development have led to the conclusions that an association exists between high cytoplasmic levels and invasive cancers, whereas the localization 
of an active form to the nucleus and its interaction with transcription factors is linked to a decrease in invasiveness (214). Consequently, as a promising prospect, drugs that can transpose FLNA from the cytoplasm to nucleus are currently under development (215).

Myosin 9 has recently attracted the attention of oncology researchers, as it has been found that this protein, classified as a cytokine involved in cytoskeletal reorganization and coded by a suppressor gene, plays an important role in the formation of cellular pseudopodia and is closely related to the progression and a poor prognosis of the majority of solid tumors (216).

Finally, the tropomyosin isoform Tpm 2.1 is considered to be another tumor suppressor, regulating the sensitivity to apoptosis beyond anoikis (217). Indeed, both the mRNA expression and protein levels of this molecule have been shown to be significantly decreased in colorectal cancer compared with paired adjacent normal tissue (218). In breast cancer, the downregulated expression of this protein is due to its promoter methylation, induced by hypoxia, leading to cell invasiveness, poor prognosis and chemoresistance (219). In another independent study, Shin et al found that the loss of Tpm2.1 increased the efficiency of migration of breast cancer cells out of the spheroids on different coated extracellular matrices (220). Finally, Mitchell et al completed these investigations by demonstrating the mechanisms through which the loss of this high molecular weight tropomyosin induced glioblastoma cell spreading and elongation in soft 3D hydrogels, recapitulating the biomechanical architecture of the brain (221).

Membrane-cytoskeleton interactions. According to Uniprot, among the cytoskeletal proteins in the list of potential biomarkers of invasiveness in the present review, three co-localize in the membrane: Cofilin-1, ezrin and vinculin.

Cofilin-1 belongs to the actin-depolymerizing family of proteins, which is essential for the dynamic changes in the actin cytoskeleton associated with the reorganization of cellular shape during the acquisition of invasiveness (222). A number of investigations have led to the conclusion that cofilin-1 expression increases in relation to cell cycle progression, migration, intravasation and the invasion of cancer cells. Gasparski et al revealed how the maturation of invadopodia, these actin-rich structures present in invasive cancer cells which degrade the surrounding ECM to facilitate invasion, was related to the downregulation of integrin $\beta 3$ expression, leading to an increase in cofilin activity (223). However, biphasic effects between the cofilin level and locomotory rate have also been observed, suggesting that the process will proceed via a complex dose- and time-dependent manner, a partially documented complex mechanism that still needs to be clarified (224).

Ezrin, which belongs to the ERM family, interacts with membrane proteins by organizing membrane-cytoskeleton-associated complexes, thus creating specialized membrane domains, and also promotes tumor metastasis (225). The role of ezrin in the mechanism of the activation of the Wnt- $\beta$-catenin signaling pathway in the context of colorectal cancer has been well documented (226). However, although ezrin is clearly associated with a poor prognosis and metastasis in different cancer types, Cihan pointed out that contradictory results remain as regards the association between ezrin expression and clinicopathological features or prognostic parameters, suggesting that this field of research requires further investigations before evaluating ezrin-based therapies (227).

The third protein of interest, vinculin, couples the ECM to the acto-myosin cytoskeleton via $\beta$-integrins and paxillin, and thus acts as a mechano-coupling and mechano-regulating protein (228). As an orchestrator of mechanical signaling events, its deregulation has important consequences on cell adhesion, contractility, motility and growth, all of which are crucial in the process of cancer metastasis (229). A positive association between estrogen receptor alpha and vinculin expression has also been demonstrated in breast cancer cells (230).

Cytoskeleton-nucleus interactions. According to Uniprot, among cytoskeletal proteins in the list of potential biomarkers of invasiveness in the present review, four of these interact with the nucleus: Nucleophosmin (NPM), heat shock protein $\beta 1$ (HspB1), actinin-4 (ACTN4) and vimentin.

NPM, an ubiquitous phosphoprotein belonging to the nucleoplasmin family of chaperones, is mainly localized in the nucleolus, a proportion of which continuously shuttles between the nucleus and the cytoplasm (231). Andersen et al initially identified this protein in a mass-spectrometry-based proteomic analysis of human centrosomes in the interphase of the cell cycle (232). NPM is involved in numerous pathways, including mRNA transport, chromatin remodeling and genome stability; however, Box et al demonstrated that its multifunctional role within the cell also included DNA repair pathways and the regulation of apoptosis in cancers (233). Of note, Werner et al reported the discovery of a translocation of the anaplastic lymphoma kinase gene $(A L K)$ with the promoter region and a proximal domain of the NPM gene (NPMI) on chromosome $5 \mathrm{q} 35$, yielding a chimeric protein that modulates numerous genes involved in the evasion of the antitumor immune response, protection from hypoxia, angiogenesis, DNA repair, and cell migration and invasiveness (234).

HspB1 (also known as Hsp-27) is a chaperone that regulates a number of fundamental cellular processes, and whose structural organization presents dynamic and complex rearrangements in response to changes in the cellular environment. Its sophisticated anti-apoptotic role acts both upstream and downstream of the mitochondria, the former effect occurring by alterations in F-actin or nucleus architecture integrity (235). Xie et al recently discovered a novel interaction between HspB1 and ezrin: The knockdown of HspB1 resulted in a decreased phosphorylation at ezrin Thr567, thus markedly suppressing the ability of ezrin to bind to the actin cytoskeleton, leading to the migration of esophageal squamous cell carcinoma cells (236).

ACTN4 is a non-muscle isoform of $\alpha$-actinin initially found concentrated in the cytoplasm of breast cancer cells migrating and located at the edge of cell clusters (239). Subsequently, Hayashida et al revealed that the $\beta$-catenin and actinin- 4 complex was highly concentrated in actin-rich protrusions at the peripheries of cell clusters, and that their colocalization in the nucleus, repressing E-cadherin expression, induced cancer invasion (238). Thomas and Robinson also demonstrated that although the two $\alpha$-actinin isoforms 1 and 4 share regulatory mechanisms, actinin- 4 exhibits a unique mechanosensory 
regulation, which warrants further, more detailed investigation (239). In parallel, Yamaguchi et al observed that the overexpression of actinin-4, but not that of actinin-1, significantly promoted the formation of invadopodia by carcinoma cells (240).

The study by Keeling et al clearly demonstrated the mechansims through which cytoskeletal organization regulated nuclear state, revealing that stress fibers and intermediate filaments modulated the mechanical properties of the nucleus and also chromatin condensation, and that actin and vimentin regulated chromatin condensation in an opposite manner (241). In a review on the role of vimentin in cell migration, Battaglia et al discussed how recent advances in microscopic techniques, combined with computational image analysis, have helped reveal the mechanisms through which vimentin promotes directed cell migration by coordinating the dynamics of actin filaments and microtubules (242).

Cytoskeleton-ECM interactions. Actin remodeling in cancer cells may be the result of the inactivation of several important actin-binding proteins such as gelsolin (243). Interest for this protein has increased as it is not only found in the cytoplasm, but also in the extracellular environment, providing future prospects for studies on its prognostic potential (244).

\section{Endoplasmic reticulum}

The endoplasmic reticulum (ER) is directly concerned with four potential biomarkers of invasiveness in the list in the present review, calnexin (CALX), BIP, serpin H1 and PDIA4 (Fig. 3), but also with four additional proteins, CALR, CLUS, TGM2 and CATD, which can be found in multiple cell compartments (Fig. 2).

Calnexin is a resident chaperone of the ER which was initially identified as an important protein involved in the reduction or suppression of antigen presentation by the major histocompatibility complex (MHC) on tumor cells (245). In a very interesting study aimed at identifying proteins preferentially expressed in a poor prognosis group of patients with lung adenocarcinoma relative to a good prognosis group (exhibiting no recurrence), Okayama et al reported that calnexin was preferentially expressed in the former, and this result was further confirmed in a cell-culture model (246). Ryan et al subsequently confirmed the prognostic significance of CALX in colorectal cancer (247). Together with calreticulin, calnexin serves as a molecular chaperone, which prevents the aggregation and export of incompletely folded proteins from the ER, a mechanism involved in the metastatic progression of tumors (248). As CALX can escape from the ER and be transported to the plasma membrane or released outside the cell, its impact on the human immune system was recently investigated by Chen et al, who reported that its upregulation was associated with the inhibition of T-cell infiltration in tumor tissues (249).

The binding immunoglobulin protein (BIP) is an ER-lumenal polypeptide chain binding protein, which belongs to the heat shock protein 70 family and interacts with numerous partners. Evidence of its role in various types of cancer began to emerge a decade ago (250). BIP is an essential factor of the translocation machinery for protein import into the ER; it regulates $\mathrm{Ca}^{2+}$ homeostasis in the ER, facilitates ER-associated protein degradation, and can initiate the unfolded protein response, inducing autophagy and crosstalking with the apoptosis machinery to assist in the cell survival decision (251). Among the numerous contributions of BIP to cancers found in the literature, Herroon et al interestingly found a link between hemeoxygenase (HO), an inducible enzyme involved in the resistance of cells against oxidative stress, whose overexpression is associated with aggressiveness, and the upregulation of BIP (252). The impact BIP on the success of anticancer therapies has been described by Chen et al, who reported that the inhibition of the hexosamine biosynthesis pathway resulted in the downregulation of BIP, which exacerbated cisplatin-induced non-small-cell lung cancer apoptosis (253).

Serpin H1 (Hsp47) specifically binds to procollagen as a resident protein of the ER, and dissociates from it in the cis-Golgi to allow fibril formation (254). A recent review of studies on this protein in the context of cancer has revealed that it plays a role in numerous steps of collagen synthesis, promoting tumor angiogenesis, growth, migration and metastatic capacity (255).

Protein disulfide isomerases (PDIs), which correct the arrangement of disulfide bonds in the ER through reductase, oxidase and isomerase functions, are implicated in the development of certain types of cancer, leading to the development of PDI inhibitors as potential novel anticancer therapies (256). Among the 21 members of this family documented so far in mammals, four of these, including PDIA6 and PDIA4, are upregulated in a variety of tumor cells. A mechanistic study demonstrated the mechanisms through which PDIA4 negatively regulates tumor cell death by inhibiting degradation and the activation of procaspases 3 and 7 via their mutual interaction (257).

Calreticulin (CALR), belonging to the damage-associated molecular patterns (DAMPs), is involved in the immunogenicity of cell death, but also represents a major predictor of a better prognosis in various types of cancer (258). However, it also plays an additional role as a pro-tumorigenic multifunctional ER protein with variable distribution as it has been shown to promote the progression of pancreatic cancer cells via the integrin/EGFR-ERK/MAPK pathway (259). The increased complexity of the functions of this pleiotropic protein was recently illustrated by the discovery that CALR functions outside the ER where its translocation to the cell membrane serves as an 'eat me' signal, promoting a silenced immune response (efferocytosis), while its effects on cytokine production are dependent on its conformation (260).

Clusterin is a highly glycosylated protein initially described as a cytoprotective chaperone-like molecule controlling cell-cell and cell-matrix interactions including adhesion (138). Subsequently, a link between this protein and TSP1 was established in the regulation of MMP9 when tumors cells interact with platelets in colonic cancer invasion (132). Clusterin has been shown to facilitate metastasis in hepatocellular carcinoma through the formation of complexes with eukaryotic translation initiation factor 3 subunit (EIF3I) and the activation of the Akt pathway, promoting the expression of MMP13 (261). Additionally, Shapiro et al reported that CLUS was overexpressed in metastatic human colorectal cancer cells in association with the presence of stem cells (262), 


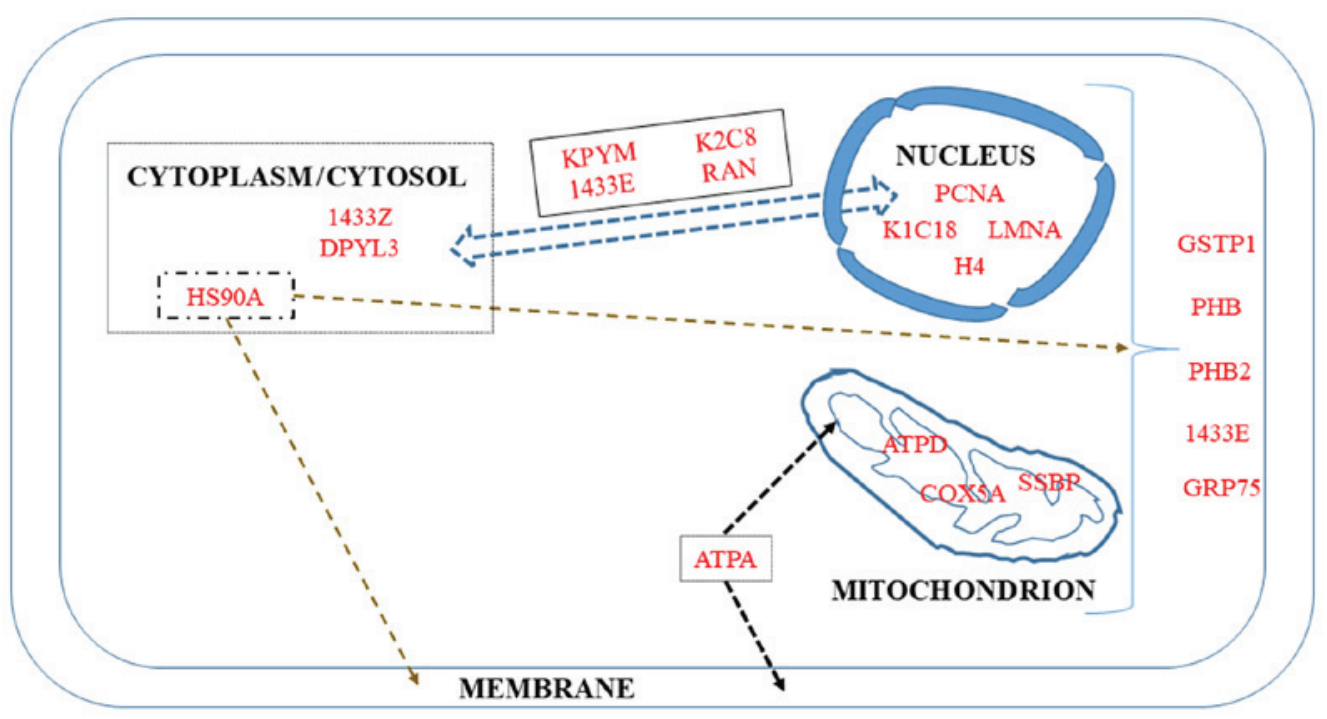

Figure 5. Mitochondrial and nuclear biomarkers and their associations with other cell compartments.

while Liu et al reported that the overexpression of clusterin promoted the invasiveness of clear cell renal carcinoma cells, an effect mediated by S100A4 (263).

\section{Mitochondrion and nucleus}

Four proteins in the list of biomarkers of invasiveness in the present review are described as macromolecules localized both in the mitochondria and nucleus, while five are restricted to the mitochondria and another five are restricted to the nucleus (Fig. 5).

Proteins shared by the two subcellular structures. The first protein in this category is the $\pi$ isoform of glutathione-S-transferase P1 (GSTP1). It belongs to a subgroup of the GST family initially involved in cellular protection against free radical and carcinogenic compounds (264). However, other functions have been discovered for this protein, including the maintenance of cellular redox homeostasis, the downregulation of which has been associated with a poor prognosis (265).

14-3-3 proteins (their names are derived from the elution profile on HPLC) are recognition structures at or near DNA replication. They are cell cycle-regulated, being maximal at the G1-S phase and minimal at the G0-G1 phase (266). This family consists mainly of seven isoforms present in mammals whose dysregulated expression contributes to tumorigenesis in different types of cancer. In particular, the downregulation of the $\varepsilon$ isoform (1433E) has been associated with lung (267) and gastric tumorigenesis (268). Although an increase or decrease may occur according to cancer type, leading to some confusion, high levels of the $\varepsilon$ isoform have been shown to predict a poor two-year overall survival of a group of chemotherapy-resistant compared with chemotherapy-sensitive patients (269).

Prohibitins are important intercellular communicators between the nucleus and mitochondria, and their many functions are highly dependent on their localization (270). Both prohibitins localize to the inner membrane, functioning as mitochondrial chaperones, although they are also present in the plasma membrane and nucleus where they act in membrane signaling and independently as transcriptional repressors of target genes, respectively (271-273). As regards the implication of PHB2 in transcription, Zhou et al recently described its substantial localization in the nucleolus, where it maintains nucleolar morphology, while promoting tumor proliferation and probably repressing differentiation in rhabdomyosarcoma cells (273). Mechanistically, PHB2 has also been reported to promote prostate cancer cells by inhibiting the expression of AKT serine/threonine kinase 2 (274). Finally, Yan et al reported that PHB2 also mediates mitophagy (275).

GRP75 (also known as Hsp70 or mortalin) plays a major role in the import and refolding of mitochondrial proteins, representing a potential serum biomarker of high prognostic value for patients with colorectal cancer (276). Additionally, Cruz et al demonstrated that this protein is a candidate biomarker of drug-resistant disease in ovarian cancer cell lines and tissues (277), while Niu et al described its involvement in modulating oncogenic Dbl-driven endocytosis (278).

Mitochondrial proteins. Among the 16 different subunits composing the ATP synthase, two were initially reported to be overexpressed in cancers and to be associated with histological grade (279), the $\alpha$-subunit, a major component of the catalytic $\mathrm{F}_{1}$ head, and the d-subunit, a major component of the $\mathrm{F}_{0}$ membranous domain (280).

Cytochrome $c$ oxidase subunit 5A (COX5A) was identified in a list of 16 mitochondrial differentially expressed proteins involved in mitochondrial oxidative stress that contribute to nasopharyngeal carcinoma metastasis (281). The increased abundance of this mitochondria-bound protein in tumorous areas and its role in the migration and invasion of non-small cell lung carcinoma cells was confirmed by Chen $e t$ al, who demonstrated that its knockdown by siRNA decreased the migration and invasion of the tumor cells (282).

Single-stranded DNA binding protein (SSBP) is another specific mitochondrial protein that maintains the structural stability of the mitochondrial genome by binding to single-stranded mtDNA. This protein regulates mitochondrial function and metabolism, and its level correlates with cancer 
cell aggressiveness. Thus, novel treatment strategies aimed at its downregulation have been proposed to increase the accumulation of ROS, decrease key glycolytic enzymes and finally, enhance the radiosensitivity of lung cancer cells (283). The role of this protein in the regulation of the base excision repair pathway (284) and in the protection against DNA damage events (285) has recently been investigated.

Nuclear proteins. In addition to Ki-67, proliferating cell nuclear antigen (PCNA) has been used in immunohistochemistry experiments, demonstrating that these two proteins are associated with each other, and with tumor grade and stage (286). Its value as an independent predictor of histological grade, recurrence rate and prognosis were subsequently confirmed in a number of studies on gastric cancer (287), hepatocellular carcinoma (288) and non-small cell lung cancer (289), highlighting in particular its interest, in association with $\mathrm{p} 53$, for the characterization of the invasive front of carcinomas (290).

The development of chromatin immunoprecipitation (ChIP) has been crucial to the study of protein-DNA interactions, leading in particular to the elucidation of the role of the A family of type V intermediate filaments (LMNA) (291) in maintaining the positional stability of DNA repair foci in mammalian nuclei (292). As the principal component of the lamina, the meshwork of proteins at the nucleoplasmic side of the inner nuclear membrane, lamins provide mechanical steadiness to the cell nucleus by protecting it from mechanical forces (293). Kim et al described the mechansims through which lamin $\mathrm{A} / \mathrm{C}$ mediates the formation of the perinuclear apical actin cables to protect the nuclear structural integrity (294). In complement to that study, Taheri et al also demonstrated the role of lamin A in determining the viscoelasticity of the chromatin network (295). Notably, Zuo et al recently reported that differences in lamin $\mathrm{A} / \mathrm{C}$ expression patterns between high and low Gleason scores in prostate cancer tissues was not associated with $L M N A$ mutations, but rather with EMT or MET processes (296).

The past few years have seen a growing interest in the study of keratin-cancer associations, with some important recent reviews on this subject $(297,298)$. In particular, certain researchers have focused on cytokeratins 8 (K2C8) and 18 (K1C18), which allow enrichment in circulating tumor cells (299). The fact that K2C8 constitutes an important part of the cytoskeleton and is involved in the migration, invasion and metastasis of small-cell lung carcinoma cells led Erlandsson et al to develop a novel treatment protocol for this type of cancer based on the use of an anti-keratin 8 antibody (300). A high expression of K1, K8 and K18 has been associated with a poor survival and a higher risk of recurrence (301), suggesting that these keratins function as sensors of changing epithelia (297). Finally, the K8/K18 pair has been demonstrated to modulate $\alpha 6 \beta 4$ integrin-mediated signaling with an impact on cancer progression (302).

Perturbations of chromatin remodeling complexes have been well-documented in malignant progression, in particular when EMT is involved (303). In these studies, H4 can undergo post-translational modifications, as it belongs to the four types of core histones forming the octamer units of nucleosome core particles (304). Together with H3, H4 is also subject to a wide variation in the abundance of acetylation of its lysine residues during the reprogramming of somatic cells (fibroblasts) into induced pluripotent stem cells (305).

\section{Miscellaneous}

The following two proteins have been suggested to be localized in the cytoplasm, although to date, there is no further documentation in the literature.

Another isoform of the 14-3-3 family of proteins mentioned above, 1433Z, which binds to several different enzymes and may reduce apoptosis, has been associated with induction of tumorigenesis in mice (306). Notably, the proteomic characterization of the tumor-promoting rearrangements of the lungs in a model of metastatic breast cancer in the mouse revealed that $1433 \mathrm{Z}$ was included in a small list of proteins differentially expressed at a stage corresponding to secretion of tumor-derived factors (307).

Dihydropyrimidinase-like 3 (DPYL3), which interacts witih ezrin, was first identified as a biomarker differentially expressed in several pancreatic ductal adenocarcinoma cell lines originating from liver metastasis in contrast to others originating from lymph node metastasis and the primary tumor (308). Of note, recent findings by Matsunuma et al revealed that the dysregulation of this protein was specific to a subset of triple-negative breast cancers characterized by low expression of claudins and E-cadherin and high levels of mesenchymal biomarkers (309), while Yang et al demonstrated that its inhibition promoted the metastasis of lung cancer (310).

\section{Extension to and links with other proteins of interest not included in the list}

The stringent methodology used in the present review to select biomarkers of interest led to the exclusion of a number of important candidates from the list. To extend the approach of the present review to additional molecules reported in the recent literature and which are involved in the cancer metastatic process, below, three examples are provided that may offer new perspectives.

A first example is represented by $\mathrm{S} 100 \mathrm{~B}$, another member of the S100 family discussed above in the section entitled 'S100 proteins'. This protein has been a subject of cancer research since 1983 and since then, 377 references have been published, with a continuous increased observed from 1995. The reason for this interest is based on the observation that S100B improves the early diagnosis, staging and prognosis of malignant melanoma $(311,312)$, and that its high expression promotes self-renewal and tumorigenicity in ovarian cancer stem cells (313). Moreover, the serum S100B level has been shown to be independently associated with a poor outcome of patients with metastatic breast cancer (314), while treatment with S100B inhibitors blocks glioma growth through the alteration of the polarization and trafficking of tumor-associated myeloid-derived cells (315). Notably, although S100B was not detected in the data described in the present review, a recent study based on an integrative analysis of transcriptomic and proteomic data of MCF7 cells submitted to acid adaptation reported high expression levels of both S100B and S100A6 in the course of EMT process affecting breast cancer cells (316). Additionally, proteomics and microarray data from breast 
cancer patients have revealed a shorter long-term survival in two subsets of patients with a combined high expression of S100B, kallikrein and S100A7 or S100A14 - S100A16 (317).

In association with S100B (318), and Annexin A2 (please also see section above entitled 'Annexins and galectins'), a second example is provided by the transmembrane receptor for advanced glycation end products (RAGE). This protein, a member of the immunoglobulin superfamily known since 1949, has been the subject of growing interest in cancer research since 2001. It is a receptor for HMGA1, increasing the migration and invasion of triple-negative breast cancer cells (319). Other RAGE ligands, such as HMGB1 (320), or S100P, S100A8 and S100A9 (321), enhance its expression, which may further lead to increased proliferation, migration and metastasis. The role of RAGE in cancer initiation and progression is now well recognized and underpins therapeutic strategies aimed at reducing AGE levels (322). The complex molecular functions of RAGE-ligand signaling arrays appear to be associated with all the hallmarks of cancer( 323,324$)$. Of note, although RAGE was not detected in either our experimental or clinical proteomic data, an increasing abundance of HMGA1 was previously found within the three rat models of malignant mesothelioma exhibiting increasing levels of invasiveness (21), a feature which is in agreement with the association described between RAGE and this nuclear protein (319).

The third example is represented by the bZIP transcription factor, nuclear factor erythroid 2-related factor 2 (NRF2), initially highlighted in studies on chemopreventive agents during investigations of the benefit conferred by consumption of fruits and vegetables on the reduced incidence of cancer (325). Interest for this protein in cancerology grew considerably, beginning in 2004, and then exponentially since 2010, reaching as many as 555 references in 2019. Recent reviews have highlighted the importance of its modulation for cancer chemoprevention and therapy (326), and the crucial role of the disruption of KEAP1 binding to NRF2 (327). To date, the NRF2 pathway represents a driver of cancer progression, metastasis and resistance to therapy (328). To provide mechanical insight into the implications of this pathway in lung cancer metastasis, Lignitto et al dissected the molecular events regulating the simultaneous loss of KEAP1 and stabilization of the transcriptional regulator Bach1 (329). These authors demonstrated that free heme promoted the physical interaction between Bach1 and Fbxo22, a substrate receptor of the CRL1 complex, by inducing Ho1, a heme-catabolizing enzyme (329). Subsequently, Wiel et al revealed that the reduction of free heme by long-term supplementation with antioxidants also stimulated metastasis by stabilizing Bach1, leading to increased glycolysis rates (330). Finally, an interesting point with regard to NRF2 is the increased abundance in CD44 antigen found in a most aggressive model of rat MM (M5-T1), compared to the two less invasive ones (F4-T2 and F5-T1) (21). This suggests a link with HMGA1 mentioned above (320), and illustrates the importance of the CD44-NRF2 axis described in breast cancer stem cell-like cells (331).

\section{Conclusions}

The aim of the present review was to establish a list of potential biomarkers of cancer invasiveness at the crossroads between literature data and experimental and clinical data, which may provide the groundwork for both basic science and translational studies. Although a number of other proteins remain outside the focus of this review, the main point is that this list represents quantitative changes which are common to different cancer types and locations. In the field of basic science, a first question concerns a number of biomarkers that are increased or decreased in most/all situations and which could therefore represent an important tool with which to understand the biological system considered as a whole (at the cancer cell or tumor scale). This approach may assist in the detection of defects within the network, the stoichiometry of components and their connectivity. Another question is why some of these biomarkers exhibit various quantitative patterns of change (increase or decrease) according to the different situations considered. On the translational side, the use of combined biomarkers could contribute to the diagnosis and prognosis of certain types of aggressive cancers, for example malignant mesothelioma, for which improvements are urgently required. This tool could also help to define and evaluate more accurate therapeutic strategies. Finally, a question which is beyond the scope of this review, is how it would be possible to prioritize these different biomarkers in a given context. This will certainly offer interesting prospects in this fascinating field of research.

\section{Acknowledgements}

Not applicable.

\section{Funding}

The present study was conducted with the support of the French National Health and Medical Research Institute (INSERM), the Ligue contre le Cancer (Ligue inter-régionale du Grand Ouest, comités 16, 29, 44, 72), and a grant from the 'Comité Féminin 49 Octobre Rose'.

\section{Availability of data and materials}

Not applicable.

\section{Authors' contributions}

DLP wrote the manuscript on the basis of experimental and clinical data obtained with the support of $\mathrm{CG}, \mathrm{AB}$ and $\mathrm{OC}$, who were also involved in drafting the review. All authors read and approved the final version of the manuscript.

\section{Ethics approval and consent to participate}

Not applicable.

\section{Patient consent for publication}

Not applicable.

\section{Competing interests}

The authors declare that they have no competing interests. 


\section{References}

1. Perou CM, Sørlie T, Eisen MB, van de Rijn M, Jeffrey SS, Rees CA, Pollack JR, Ross DT, Johnsen H, Akslen LA, et al: Molecular portraits of human breast tumours. Nature 406: 747-752, 2000

2. Coates AS, Winer EP, Goldhirsch A, Gelber RD, Gnant M, Piccart-Gebhart M, Thürlimann B, Senn H-J, André F, Baselga J, et al; Panel Members: Tailoring therapies - improving the management of early breast cancer: St Gallen International Expert Consensus on the Primary Therapy of Early Breast Cancer 2015. Ann Oncol 26: 1533-1546, 2015.

3. Zhang B, Wang J, Wang X, Zhu J, Liu Q, Shi Z, Chambers MC Zimmerman LJ, Shaddox KF, Kim S, et al; NCI CPTAC: Proteogenomic characterization of human colon and rectal cancer. Nature 513: 382-387, 2014

4. Johansson HJ, Socciarelli F, Vacanti NM, Haugen MH, Zhu Y, Siavelis I, Fernandez-Woodbridge A, Aure MR, Sennblad B, Vesterlund M, et al; Consortia Oslo Breast Cancer Research Consortium (OSBREAC): Breast cancer quantitative proteome and proteogenomic landscape. Nat Commun 10: 1600, 2019.

5. Mann M: Quantitative proteomics? Nat Biotechnol 17: 954-955, 1999.

6. Monti C,Zilocchi M, Colugnat I and Alberio T: Proteomics turns functional. J Proteomics 198: 36-44, 2019.

7. Simpson RJ and Dorow DS: Cancer proteomics: From signaling networks to tumor markers. Trends Biotechnol 19 (Suppl): S40-S48, 2001.

8. Cheung CHY and Juan HF: Quantitative proteomics in lung cancer. J Biomed Sci 24: 37, 2017.

9. Geiger T and Geiger B: Towards elucidation of functional molecular signatures of the adhesive-migratory phenotype of malignant cells. Semin Cancer Biol 20: 146-152, 2010.

10. Jazurek M, Ciesiolka A, Starega-Roslan J, Bilinska K and Krzyzosiak WJ: Identifying proteins that bind to specific RNAs focus on simple repeat expansion diseases. Nucleic Acids Res 44: 9050-9070, 2016.

11. Abazova N and Krijgsveld J: Advances in stem cell proteomics. Curr Opin Genet Dev 46: 149-155, 2017.

12. Eubanks CG, Dayebgadoh G, Liu X and Washburn MP Unravelling the biology of chromatin in health and cancer using proteomic approaches. Expert Rev Proteomics 14: 905-915, 2017

13. Gómez-Serrano M, Camafeita E, Loureiro M and Peral B: Mitoproteomics: Tackling mitochondrial dysfunction in human disease. Oxid Med Cell Longev 2018: 1435934, 2018.

14. Suwakulsiri W, Rai A, Chen M, Greening DW and Simpson RJ Proteomic profiling reveals key cancer progression modulators in shed microvesicles released from isogenic human primary and metastatic colorectal cancer cell lines. Biochim Biophys Acta Proteins Proteom 1867: 140171, 2019.

15. Li Z, Li N, Shen L and Fu J: Quantitative proteomic analysis identifies MAPK15 as a potential regulator of radioresistance in nasopharyngeal carcinoma cells. Front Oncol 8: 548, 2018.

16. Gillet L, Navarro P, Tate S, Röst H, Selevsek N, Reiter L, Bonner R and Aebersold R: Targeted data extraction of the MS/MS spectra generated by data-independent acquisition: a new concept for consistent and accurate proteome analysis. Mol Cell Proteomics 11: O111.016717, 2012.

17. Ludwig C, Gillet L, Rosenberger G, Amon S, Collins BC and Aebersold R: Data-independent acquisition-based SWATH-MS for quantitative proteomics: A tutorial. Mol Syst Biol 14: e8126, 2018 .

18. Krisp C and Molloy MP: SWATH mass spectrometry for proteomics of non-depleted plasma. Methods Mol Biol 1619: 373-383, 2017

19. Jamwal R, Barlock BJ, Adusumalli S, Ogasawara K, Simons BL and Akhlaghi F: Multiplex and label-free relative quantification approach for studying protein abundance of drug metabolizing enzymes in human liver microsomes using SWATH-MS J Proteome Res 16: 4134-4143, 2017.

20. Wang L, Skotland T, Berge V, Sandvig K and Llorente A: Exosomal proteins as prostate cancer biomarkers in urine: From mass spectrometry discovery to immunoassay-based validation. Eur J Pharm Sci 98: 80-85, 2017.

21. Nader JS, Abadie J, Deshayes S, Boissard A, Blandin S, Blanquart C Boisgerault $\mathrm{N}$, Coqueret $\mathrm{O}$, Guette $\mathrm{C}$, Grégoire $\mathrm{M}$, et al: Characterization of increasing stages of invasiveness identifies stromal/cancer cell crosstalk in rat models of mesothelioma. Oncotarget 9: 16311-16329, 2018.
22. Besson D, Pavageau A-H, Valo I, Bourreau A, Bélanger A, Eymerit-Morin C, Moulière A, Chassevent A, Boisdron-Celle M, Morel A, et al: A quantitative proteomic approach of the different stages of colorectal cancer establishes OLFM4 as a new nonmetastatic tumor marker. Mol Cell Proteomics 10: 009712, 2011

23. Valo I, Raro P, Boissard A, Maarouf A, Jézéquel P, Verriele V, Campone M, Coqueret O and Guette C: OLFM4 expression in ductal carcinoma in situ and in invasive breast cancer cohorts by a SWATH-based proteomic approach. Proteomics 19: e1800446, 2019.

24. Powell AA, Talasaz AH, Zhang H, Coram MA, Reddy A, Deng G, Telli ML, Advani RH, Carlson RW, Mollick JA, et al: Single cell profiling of circulating tumor cells: Transcriptional heterogeneity and diversity from breast cancer cell lines. PLoS One 7: e33788, 2012.

25. Lukanidin E and Sleeman JP: Building the niche: The role of the S100 proteins in metastatic growth. Semin Cancer Biol 22: 216-225, 2012

26. Bresnick AR, Weber DJ and Zimmer DB: S100 proteins in cancer. Nat Rev Cancer 15: 96-109, 2015.

27. Shabani F, Farasat A, Mahdavi M and Gheibi N: Calprotectin (S100A8/S100A9): A key protein between inflammation and cancer. Inflamm Res 67: 801-812, 2018.

28. Björk P, Källberg E, Wellmar U, Riva M, Olsson A, He Z, Törngren M, Liberg D, Ivars F and Leanderson T: Common interactions between S100A4 and S100A9 defined by a novel chemical probe. PLoS One 8: e63012, 2013.

29. Fei F, Qu J, Zhang M, Li Y and Zhang S: S100A4 in cancer progression and metastasis: A systematic review. Oncotarget 8: 73219-73239, 2017

30. Yoshimura H, Otsuka A, Michishita M, Yamamoto $M$, Ashizawa M, Zushi M, Moriya M, Azakami D, Ochiai K, Matsuda Y, et al: Expression and roles of S100A4 in anaplastic cells of canine mammary carcinomas. Vet Pathol 56: 389-398, 2019.

31. Liu Y and Cao X: Characteristics and significance of the pre-metastatic niche. Cancer Cell 30: 668-681, 2016.

32. Hansen MT, Forst B, Cremers N, Quagliata L, Ambartsumian N, Grum-Schwensen B, Klingelhöfer J, Abdul-Al A, Herrmann P, Osterland M, et al: A link between inflammation and metastasis: Serum amyloid A1 and A3 induce metastasis, and are targets of metastasis-inducing S100A4. Oncogene 34: 424-435, 2015.

33. Mahmood MQ, Ward C, Muller HK, Sohal SS and Walters EH: Epithelial mesenchymal transition (EMT) and non-small cell lung cancer (NSCLC): A mutual association with airway disease. Med Oncol 34: 45, 2017.

34. Liu M, Liu J, Yang B, Gao X, Gao LL, Kong QY, Zhang P and $\mathrm{Li} \mathrm{H}$ : Inversed expression patterns of S100A4 and E-cadherin in cervical cancers: Implication in epithelial-mesenchymal transition. Anat Rec (Hoboken) 300: 2184-2191, 2017.

35. Roulois D, Deshayes S, Guilly MN, Nader JS, Liddell C, Robard M, Hulin P, Ouacher A, Le Martelot V, Fonteneau JF, et al: Characterization of preneoplastic and neoplastic rat mesothelial cell lines: The involvement of TETs, DNMTs, and 5-hydroxymethylcytosine. Oncotarget 7: 34664-34687, 2016.

36. Donato R, Sorci G and Giambanco I: S100A6 protein: Functional roles. Cell Mol Life Sci 74: 2749-2760, 2017.

37. Lyu X, Li H, Ma X, Li X, Gao Y, Ni D, Shen D, Gu L, Wang B, Zhang Y, et al: High-level S100A6 promotes metastasis and predicts the outcome of T1-T2 stage in clear cell renal cell carcinoma. Cell Biochem Biophys 71: 279-290, 2015.

38. Luo X, Sharff KA, Chen J, He T-C and Luu HH: S100A6 expression and function in human osteosarcoma. Clin Orthop Relat Res 466: 2060-2070, 2008

39. Zhang J, Zhang K, Jiang X and Zhang J: S100A6 as a potential serum prognostic biomarker and therapeutic target in gastric cancer. Dig Dis Sci 59: 2136-2144, 2014.

40. Popa SJ, Stewart SE and Moreau K: Unconventional secretion of annexins and galectins. Semin Cell Dev Biol 83: 42-50, 2018.

41. Gerke V, Creutz CE and Moss SE: Annexins: Linking $\mathrm{Ca}^{2+}$ signalling to membrane dynamics. Nat Rev Mol Cell Biol 6: 449-461, 2005.

42. Qi H, Liu S, Guo C, Wang J, Greenaway FT and Sun M-Z: Role of annexin A6 in cancer (Review). Oncol Lett 10: 1947-1952, 2015.

43. Grewal T, Hoque M, Conway JRW, Reverter M, Wahba M, Beevi SS, Timpson P, Enrich C and Rentero C: Annexin A6-A multifunctional scaffold in cell motility. Cell Adhes Migr 11: 288-304, 2017. 
44. Sakwe AM, Koumangoye R, Guillory B and Ochieng $\mathrm{J}$ : Annexin A6 contributes to the invasiveness of breast carcinoma cells by influencing the organization and localization of functional focal adhesions. Exp Cell Res 317: 823-837, 2011.

45. Keklikoglou I, Cianciaruso C, Güç E, Squadrito ML, Spring LM, Tazzyman S, Lambein L, Poissonnier A, Ferraro GB, Baer C, et al: Chemotherapy elicits pro-metastatic extracellular vesicles in breast cancer models. Nat Cell Biol 21: 190-202, 2019.

46. Koumangoye RB, Nangami GN, Thompson PD, Agboto VK, Ochieng J and Sakwe AM: Reduced annexin A6 expression promotes the degradation of activated epidermal growth factor receptor and sensitizes invasive breast cancer cells to EGFR-targeted tyrosine kinase inhibitors. Mol Cancer 12: 167, 2013.

47. García-Melero A, Reverter M, Hoque M, Meneses-Salas E, Koese M, Conway JRW, Johnsen CH, Alvarez-Guaita A, Morales-Paytuvi F, Elmaghrabi YA, et al: Annexin A6 and late endosomal cholesterol modulate integrin recycling and cell migration. J Biol Chem 291: 1320-1335, 2016.

48. Widatalla SE, Korolkova OY, Whalen DS, Goodwin JS, Williams KP, Ochieng J and Sakwe AM: Lapatinib-induced annexin A6 upregulation as an adaptive response of triple-negative breast cancer cells to EGFR tyrosine kinase inhibitors. Carcinogenesis 40: 998-1009, 2019.

49. Leca J,Martinez S, Lac S, Nigri J,Secq V,Rubis M,Bressy C, Sergé A, Lavaut M-N, Dusetti N, et al: Cancer-associated fibroblast-derived annexin $\mathrm{A}^{+}$extracellular vesicles support pancreatic cancer aggressiveness. J Clin Invest 126: 4140-4156, 2016.

50. Whalen DS, Widatalla SE, Korolkova OY, Nangami GS, Beasley HK, Williams SD, Virgous C, Lehmann BD, Ochieng J and Sakwe AM: Implication of calcium activated RasGRF2 in Annexin A6-mediated breast tumor cell growth and motility. Oncotarget 10: 133-151, 2019.

51. Sheikh MH and Solito E: Annexin A1: Uncovering the many talents of an old protein. Int J Mol Sci 19: 1045, 2018.

52. Babbin BA, Lee WY, Parkos CA, Winfree LM, Akyildiz A, Perretti M and Nusrat A: Annexin I regulates SKCO-15 cell invasion by signaling through formyl peptide receptors. J Biol Chem 281: 19588-19599, 2006

53. Guo C, Liu S and Sun M-Z: Potential role of Anxa1 in cancer. Future Oncol 9: 1773-1793, 2013.

54. Swa HLF, Shaik AA, Lim LHK and Gunaratne J: Mass spectrometry based quantitative proteomics and integrative network analysis accentuates modulating roles of annexin-1 in mammary tumorigenesis. Proteomics 15: 408-418, 2015.

55. Okano M, Kumamoto K, Saito M, Onozawa H, Saito K, Abe N, Ohtake T and Takenoshita S: Upregulated Annexin A1 promotes cellular invasion in triple-negative breast cancer. Oncol Rep 33: 1064-1070, 2015.

56. Tu Y, Johnstone CN and Stewart AG: Annexin A1 influences in breast cancer: Controversies on contributions to tumour, host and immunoediting processes. Pharmacol Res 119: 278-288, 2017.

57. Liao S-H, Zhao X-Y, Han Y-H, Zhang J, Wang L-S, Xia L, Zhao K-W, Zheng Y, Guo M and Chen G-Q: Proteomics-based identification of two novel direct targets of hypoxia-inducible factor-1 and their potential roles in migration/invasion of cancer cells. Proteomics 9: 3901-3912, 2009.

58. Xu Y, Wang J, Xu Y, Xiao H, Li J and Wang Z: Screening critical genes associated with malignant glioma using bioinformatics analysis. Mol Med Rep 16: 6580-6589, 2017.

59. Kang H, Ko J and Jang S-W: The role of annexin A1 in expression of matrix metalloproteinase-9 and invasion of breast cancer cells. Biochem Biophys Res Commun 423: 188-194, 2012.

60. Grindheim AK, Saraste J and Vedeler A: Protein phosphorylation and its role in the regulation of Annexin A2 function. Biochim Biophys Acta, Gen Subj 1861A: A2515-A2529, 2017.

61. Christensen MV, Høgdall CK, Jochumsen KM and Høgdall EVS: Annexin A2 and cancer: A systematic review. Int J Oncol 52: $5-18,2018$.

62. Maule F, Bresolin S, Rampazzo E, Boso D, Della Puppa A, Esposito G, Porcù E, Mitola S, Lombardi G, Accordi B, et al: Annexin 2A sustains glioblastoma cell dissemination and proliferation. Oncotarget 7: 54632-54649, 2016.

63. Liu Y, Li H, Ban Z, Nai M, Yang L, Chen Y and Xu Y: Annexin A2 inhibition suppresses ovarian cancer progression via regulating $\beta$-catenin/EMT. Oncol Rep 37: 3643-3650, 2017.

64. Rocha MR, Barcellos-de-Souza P, Sousa-Squiavinato ACM, Fernandes PV, de Oliveira IM, Boroni M and Morgado-Diaz JA: Annexin A2 overexpression associates with colorectal cancer invasiveness and TGF- $\beta$ induced epithelial mesenchymal transition via Src/ANXA2/STAT3. Sci Rep 8: 11285, 2018.
65. Yoneura N, Takano S, Yoshitomi H, Nakata Y, Shimazaki R, Kagawa S, Furukawa K, Takayashiki T, Kuboki S, Miyazaki M, etal: Expression of annexin II and stromal tenascin C promotes epithelial to mesenchymal transition and correlates with distant metastasis in pancreatic cancer. Int J Mol Med 42: 821-830, 2018.

66. Zhang Q, Zhao Z, Ma Y, Wang H, Ma J, He X and Zhang D: Combined expression of S100A4 and Annexin A2 predicts disease progression and overall survival in patients with urothelial carcinoma. Urol Oncol 32: 798-805, 2014.

67. Zhang Q, Ye Z, Yang Q, He X, Wang H and Zhao Z: Upregulated expression of annexin II is a prognostic marker for patients with gastric cancer. World J Surg Oncol 10: 103, 2012.

68. Korwar AM, Bhonsle HS, Chougale AD, Kote SS, Gawai KR, Ghole VS, Koppikar CB and Kulkarni MJ: Analysis of AGE modified proteins and RAGE expression in HER2/neu negative invasive ductal carcinoma. Biochem Biophys Res Commun 419: 490-494, 2012.

69. Sheng SH and Zhu HL: Proteomic analysis of pleural effusion from lung adenocarcinoma patients by shotgun strategy. Clin Transl Oncol 16: 153-157, 2014.

70. Ricciardelli C, Lokman NA, Ween MP and Oehler MK: WOMEN IN CANCER THEMATIC REVIEW: Ovarian cancer-peritoneal cell interactions promote extracellular matrix processing. Endocr Relat Cancer 23: T155-T168, 2016.

71. van den Brûle FA, Buicu C, Berchuck A, Bast RC, Deprez M, Liu F-T, Cooper DNW, Pieters C, Sobel ME and Castronovo V: Expression of the 67-kD laminin receptor, galectin-1, and galectin-3 in advanced human uterine adenocarcinoma. Hum Pathol 27: 1185-1191, 1996.

72. Camby I, Belot N, Rorive S, Lefranc F, Maurage C-A, Lahm H, Kaltner H, Hadari Y, Ruchoux MM, Brotchi J, et al: Galectins are differentially expressed in supratentorial pilocytic astrocytomas, astrocytomas, anaplastic astrocytomas and glioblastomas, and significantly modulate tumor astrocyte migration. Brain Pathol 11: 12-26, 2001.

73. Astorgues-Xerri L, Riveiro ME, Tijeras-Raballand A, Serova M, Neuzillet C, Albert S, Raymond E and Faivre S: Unraveling galectin-1 as a novel therapeutic target for cancer. Cancer Treat Rev 40: 307-319, 2014

74. Cousin JM and Cloninger MJ: The role of galectin-1 in cancer progression, and synthetic multivalent systems for the study of galectin-1. Int J Mol Sci 17: 1566, 2016.

75. Bhat R, Belardi B, Mori H, Kuo P, Tam A, Hines WC, Le Q-T, Bertozzi CR and Bissell MJ: Nuclear repartitioning of galectin-1 by an extracellular glycan switch regulates mammary morphogenesis. Proc Natl Acad Sci USA 113: E4820-E4827, 2016.

76. Shen K-H, Li C-F, Chien L-H, Huang C-H, Su C-C, Liao AC and Wu T-F: Role of galectin-1 in urinary bladder urothelial carcinoma cell invasion through the JNK pathway. Cancer Sci 107: 1390-1398, 2016

77. Chong Y, Tang D, Xiong Q, Jiang X, Xu C, Huang Y, Wang J, Zhou H, Shi Y, Wu X, et al: Galectin-1 from cancer-associated fibroblasts induces epithelial-mesenchymal transition through $\beta 1$ integrin-mediated upregulation of Gli1 in gastric cancer. J Exp Clin Cancer Res 35: 175, 2016.

78. Chong Y, Tang D, Gao J, Jiang X, Xu C, Xiong Q, Huang Y, Wang J, Zhou H, Shi Y, et al: Galectin-1 induces invasion and the epithelial-mesenchymal transition in human gastric cancer cells via non-canonical activation of the hedgehog signaling pathway. Oncotarget 7: 83611-83626, 2016.

79. Zhang P-F, Li K-S, Shen YH, Gao P-T, Dong Z-R, Cai J-B, Zhang C, Huang X-Y, Tian M-X, Hu Z-Q, et al: Galectin-1 induces hepatocellular carcinoma EMT and sorafenib resistance by activating FAK/PI3K/AKT signaling. Cell Death Dis 7: e2201, 2016.

80. Qian D, Lu Z, Xu Q, Wu P, Tian L, Zhao L, Cai B, Yin J, Wu Y, Staveley-O'Carroll KF, et al: Galectin-1-driven upregulation of SDF-1 in pancreatic stellate cells promotes pancreatic cancer metastasis. Cancer Lett 397: 43-51, 2017.

81. Noda Y, Kishino M, Sato S, Hirose K, Sakai M, Fukuda Y, Murakami S and Toyosawa S: Galectin-1 expression is associated with tumour immunity and prognosis in gingival squamous cell carcinoma. J Clin Pathol 70: 126-133, 2017.

82. Song L, Tang JW, Owusu L, Sun M-Z, Wu J and Zhang J: Galectin-3 in cancer. Clin Chim Acta 431: 185-191, 2014.

83. Ajani JA, Estrella JS, Chen Q, Correa AM, Ma L, Scott AW, Jin J, Liu B, Xie M, Sudo K, et al: Galectin-3 expression is prognostic in diffuse type gastric adenocarcinoma, confers aggressive phenotype, and can be targeted by YAP1/BET inhibitors. Br J Cancer 118: 52-61, 2018. 
84. Ruvolo PP: Galectin 3 as a guardian of the tumor microenvironment. Biochim Biophys Acta 1863: 427-437, 2016.

85. Cardoso AC, Andrade LN, Bustos SO and Chammas R: Galectin-3 determines tumor cell adaptive strategies in stressed tumor microenvironments. Front Oncol 6: 127, 2016.

86. Mackay A, Jones C, Dexter T, Silva RL, Bulmer K, Jones A, Simpson P, Harris RA, Jat PS, Neville AM, et al: cDNA microarray analysis of genes associated with $E R B B 2$ (HER2/neu) overexpression in human mammary luminal epithelial cells. Oncogene 22: 2680-2688, 2003.

87. Nomura $\mathrm{T}$ and Katunuma N: Involvement of cathepsins in the invasion, metastasis and proliferation of cancer cells. J Med Invest 52: 1-9, 2005.

88. Derocq D, Prébois C, Beaujouin M, Laurent-Matha V, Pattingre S, Smith GK and Liaudet-Coopman E: Cathepsin D is partly endocytosed by the LRP1 receptor and inhibits LRP1-regulated intramembrane proteolysis. Oncogene 31: 3202-3212, 2012

89. Dubey V and Luqman S: Cathepsin D as a promising target for the discovery of novel anticancer agents. Curr Cancer Drug Targets 17: 404-422, 2017.

90. Brown KD: Transglutaminase 2 and NF- $\kappa$ B: An odd couple that shapes breast cancer phenotype. Breast Cancer Res Treat 137: 329-336, 2013

91. Yang P, Yu D, Zhou J, Zhuang S and Jiang T: TGM2 interference regulates the angiogenesis and apoptosis of colorectal cancer via Wnt/ $\beta$-catenin pathway. Cell Cycle 18: 1122-1134, 2019.

92. Eble JA and Niland S: The extracellular matrix in tumor progression and metastasis. Clin Exp Metastasis 36: 171-198, 2019.

93. Garamszegi N, Garamszegi SP, Shehadeh LA and Scully SP: Extracellular matrix-induced gene expression in human breast cancer cells. Mol Cancer Res 7: 319-329, 2009.

94.Giehl K and Menke A: Microenvironmental regulation of E-cadherin-mediated adherens junctions. Front Biosci 13 3975-3985, 2008

95. Yang S, Shin J, Park KH, Jeung H-C, Rha SY, Noh SH, Yang WI and Chung HC: Molecular basis of the differences between normal and tumor tissues of gastric cancer. Biochim Biophys Acta 1772: 1033-1040, 2007

96. Liang Y, Diehn M, Bollen AW, Israel MA and Gupta N: Type I collagen is overexpressed in medulloblastoma as a component of tumor microenvironment. J Neurooncol 86 : 133-141, 2008.

97. Montgomery H, Rustogi N, Hadjisavvas A, Tanaka K, Kyriacou K and Sutton CW: Proteomic profiling of breast tissue collagens and site-specific characterization of hydroxyproline residues of collagen alpha-1-(I). J Proteome Res 11: 5890-5902, 2012.

98. Mitsuhashi A, Goto H, Saijo A, Trung VT, Aono Y, Ogino H, Kuramoto T, Tabata S, Uehara H, Izumi K, et al: Fibrocyte-like cells mediate acquired resistance to anti-angiogenic therapy with bevacizumab. Nat Commun 6: 8792, 2015.

99. Rong L, Huang W, Tian S, Chi X, Zhao P and Liu F: COL1A2 is a novel biomarker to improve clinical prediction in human gastric cancer: Integrating bioinformatics and meta-analysis. Pathol Oncol Res 24: 129-134, 2018.

100. Yang X, Staren ED, Howard JM, Iwamura T, Bartsch JE and Appert HE: Invasiveness and MMP expression in pancreatic carcinoma. J Surg Res 98: 33-39, 2001.

101.Parmo-Cabañas M, Molina-Ortiz I, Matías-Román S, García-Bernal D, Carvajal-Vergara X, Valle I, Pandiella A Arroyo AG and Teixidó J: Role of metalloproteinases MMP-9 and MT1-MMP in CXCL12-promoted myeloma cell invasion across basement membranes. J Pathol 208: 108-118, 2006.

102. Ren F, Tang R, Zhang X, Madushi WM, Luo D, Dang Y, Li Z, Wei $\mathrm{K}$ and Chen G: Overexpression of MMP family members functions as prognostic biomarker for breast cancer patients: A systematic review and meta-analysis. PLoS One 10: e0135544, 2015

103.Liu H-Y, Gu W-J, Wang C-Z, Ji X-J and Mu Y-M: Matrix metalloproteinase- 9 and -2 and tissue inhibitor of matrix metalloproteinase- 2 in invasive pituitary adenomas: A systematic review and meta-analysis of case-control trials. Medicine (Baltimore) 95: e3904, 2016

104.Delassus GS, Cho H, Park J and Eliceiri GL: New pathway links from cancer-progression determinants to gene expression of matrix metalloproteinases in breast cancer cells. J Cell Physiol 217: 739-744, 2008.
105. Franco-Barraza J, Valdivia-Silva JE, Zamudio-Meza H, Castillo A, García-Zepeda EA, Benítez-Bribiesca L and Meza I: Actin cytoskeleton participation in the onset of IL-1beta induction of an invasive mesenchymal-like phenotype in epithelial MCF-7 cells. Arch Med Res 41: 170-181, 2010.

106. Matsuura I, Lai C-Y and Chiang K-N: Functional interaction between Smad3 and S100A4 (metastatin-1) for TGF-beta-mediated cancer cell invasiveness. Biochem J 426: $327-335,2010$

107. Oskarsson T: Extracellular matrix components in breast cancer progression and metastasis. Breast 22 (Suppl 2): S66-S72, 2013.

108. Kaplan RN, Riba RD, Zacharoulis S, Bramley AH, Vincent L, Costa C, MacDonald DD, Jin DK, Shido K, Kerns SA, et al: VEGFR1-positive haematopoietic bone marrow progenitors initiate the pre-metastatic niche. Nature 438: 820-827, 2005.

109. Topalovski M and Brekken RA: Matrix control of pancreatic cancer: New insights into fibronectin signaling. Cancer Lett 381 252-258, 2016

110. Liao Y-X, Zhang Z-P, Zhao J and Liu J-P: Effects of fibronectin 1 on cell proliferation, senescence and apoptosis of human glioma cells through the PI3K/AKT signaling pathway. Cell Physio Biochem 48: 1382-1396, 2018.

111. Sercu S, Zhang L and Merregaert J: The extracellular matrix protein 1: Its molecular interaction and implication in tumor progression. Cancer Invest 26: 375-384, 2008

112. Bergamaschi A, Tagliabue E, Sørlie T, Naume B, Triulzi T, Orlandi R, Russnes HG, Nesland JM, Tammi R, Auvinen P, et al: Extracellular matrix signature identifies breast cancer subgroups with different clinical outcome. J Pathol 214: 357-367, 2008.

113. Lal G, Hashimi S, Smith BJ, Lynch CF, Zhang L, Robinson RA and Weigel RJ: Extracellular matrix 1 (ECM1) expression is a novel prognostic marker for poor long-term survival in breast cancer: A Hospital-based Cohort Study in Iowa. Ann Surg Oncol 16: 2280-2287, 2009.

114. Lee KM, Nam K, Oh S, Lim J, Kim RK, Shim D, Choi JH, Lee S-J, Yu J-H, Lee JW, et al: ECM1 regulates tumor metastasis and CSC-like property through stabilization of $\beta$-catenin. Oncogene 34: 6055-6065, 2015.

115. Chen $\mathrm{H}$, Jia $\mathrm{W}$ and Li J: ECM1 promotes migration and invasion of hepatocellular carcinoma by inducing epithelial-mesenchymal transition. World J Surg Oncol 14: 195, 2016.

116. Gómez-Contreras P, Ramiro-Díaz JM, Sierra A, Stipp C, DomannFE, Weigel RJ and Lal G: Extracellular matrix 1 (ECM1) regulates the actin cytoskeletal architecture of aggressive breast cancer cells in part via S100A4 and Rho-family GTPases. Clin Exp Metastasis 34: 37-49, 2017.

117. Gan L, Meng J, Xu M, Liu M, Qi Y, Tan C, Wang Y, Zhang P, Weng W, Sheng W, et al: Extracellular matrix protein 1 promotes cell metastasis and glucose metabolism by inducing integrin $\beta 4 / \mathrm{FAK} / \mathrm{SOX} 2 / \mathrm{HIF}-1 \alpha$ signaling pathway in gastric cancer. Oncogene 37: 744-755, 2018.

118. Troup S, Njue C, Kliewer EV, Parisien M, Roskelley C, Chakravarti S, Roughley PJ, Murphy LC and Watson PH: Reduced expression of the small leucine-rich proteoglycans, lumican, and decorin is associated with poor outcome in node-negative invasive breast cancer. Clin Cancer Res 9: 207-214, 2003

119. Vuillermoz B, Khoruzhenko A, D'Onofrio M-F, Ramont L, Venteo L, Perreau C, Antonicelli F, Maquart F-X and Wegrowski Y: The small leucine-rich proteoglycan lumican inhibits melanoma progression. Exp Cell Res 296: 294-306, 2004.

120. Radwanska A, Litwin M, Nowak D, Baczynska D, Wegrowski Y, Maquart F-X and Malicka-Blaszkiewicz M: Overexpression of lumican affects the migration of human colon cancer cells through up-regulation of gelsolin and filamentous actin reorganization. Exp Cell Res 318: 2312-2323, 2012

121. Coulson-Thomas VJ, Coulson-Thomas YM, Gesteira TF, Andrade de Paula CA, Carneiro CR, Ortiz V, Toma L, Kao WW and Nader HB: Lumican expression, localization and antitumor activity in prostate cancer. Exp Cell Res 319: 967-981, 2013.

122. de Wit M, Carvalho B, Delis-van Diemen PM, van Alphen C, Beliën JAM, Meijer GA and Fijneman RJA: Lumican and versican protein expression are associated with colorectal adenoma-to-carcinoma progression. PLoS One 12: e0174768, 2017.

123. Farace C, Oliver JA, Melguizo C, Alvarez P, Bandiera P, Rama AR, Malaguarnera G, Ortiz R, Madeddu R and Prados J: Microenvironmental modulation of decorin and lumican in Temozolomide-resistant glioblastoma and neuroblastoma cancer stem-like cells. PLoS One 10: e0134111, 2015. 
124. Jeanne A, Untereiner V, Perreau C, Proult I, Gobinet C, Boulagnon-Rombi C, Terryn C, Martiny L, Brézillon S and Dedieu S: Lumican delays melanoma growth in mice and drives tumor molecular assembly as well as response to matrix-targeted TAX2 therapeutic peptide. Sci Rep 7: 7700, 2017.

125. Gritsenko PG, Ilina O and Friedl P: Interstitial guidance of cancer invasion. J Pathol 226: 185-199, 2012.

126.Ruan K, Bao S and Ouyang G: The multifaceted role of periostin in tumorigenesis. Cell Mol Life Sci 66: 2219-2230, 2009.

127. Kim G-E, Lee JS, Park MH and Yoon JH: Epithelial periostin expression is correlated with poor survival in patients with invasive breast carcinoma. PLoS One 12: e0187635, 2017.

128. Mino M, Kanno K, Okimoto K, Sugiyama A, Kishikawa N, Kobayashi T, Ono J, Izuhara K, Kobayashi T, Ohigashi T, et al: Periostin promotes malignant potential by induction of epithelial-mesenchymal transition in intrahepatic cholangiocarcinoma. Hepatol Commun 1: 1099-1109, 2017.

129. Sid B, Sartelet H, Bellon G, El Btaouri H, Rath G, Delorme N, Haye B and Martiny L: Thrombospondin 1: A multifunctional protein implicated in the regulation of tumor growth. Crit Rey Oncol Hematol 49: 245-258, 2004.

130. Okada K, Hirabayashi K, Imaizumi T, Matsuyama M, Yazawa N, Dowaki S, Tobita K, Ohtani Y, Tanaka M, Inokuchi S, et al: Stromal thrombospondin-1 expression is a prognostic indicator and a new marker of invasiveness in intraductal papillary-mucinous neoplasm of the pancreas. Biomed Res 31: $13-19,2010$

131.Firlej V, Mathieu JRR, Gilbert C, Lemonnier L, Nakhlé J, Gallou-Kabani C, Guarmit B, Morin A, Prevarskaya N, Delongchamps NB, et al: Thrombospondin-1 triggers cell migration and development of advanced prostate tumors. Cancer Res 71: 7649-7658, 2011.

132. Radziwon-Balicka A, Santos-Martinez MJ, Corbalan JJ, O'Sullivan S, Treumann A, Gilmer JF, Radomski MW and Medina C: Mechanisms of platelet-stimulated colon cancer invasion: Role of clusterin and thrombospondin 1 in regulation of the P38MAPK-MMP-9 pathway. Carcinogenesis 35: 324-332, 2014

133. Joshi R, Goihberg E, Ren W, Pilichowska M and Mathew P: Proteolytic fragments of fibronectin function as matrikines driving the chemotactic affinity of prostate cancer cells to human bone marrow mesenchymal stromal cells via the $\alpha 5 \beta 1$ integrin. Cell Adhes Migr 11: 305-315, 2017

134. Lebdai S, Verhoest G, Parikh H, Jacquet SF, Bensalah K, Chautard D, Rioux Leclercq N, Azzouzi AR and Bigot P: Identification and validation of TGFBI as a promising prognosis marker of clear cell renal cell carcinoma. Urol Oncol 33: 69.e11-69.e18, 2015

135. Nummela P, Lammi J, Soikkeli J, Saksela O, Laakkonen P and Hölttä E: Transforming growth factor beta-induced (TGFBI) is an anti-adhesive protein regulating the invasive growth of melanoma cells. Am J Pathol 180: 1663-1674, 2012.

136.Klamer SE, Kuijk CG, Hordijk PL, van der Schoot CE, von Lindern M, van Hennik PB and Voermans C: BIGH3 modulates adhesion and migration of hematopoietic stem and progenitor cells. Cell Adhes Migr 7: 434-449, 2013.

137. Kontostathi G, Zoidakis J, Makridakis M, Lygirou V, Mermelekas G, Papadopoulos T, Vougas K, Vlamis-Gardikas A, Drakakis P, Loutradis D, et al: Cervical cancer cell line secretome highlights the roles of transforming growth factor-beta-induced protein ig-h3, peroxiredoxin-2, and NRF2 on cervical carcinogenesis. BioMed Res Int 2017: 4180703, 2017.

138. Mathias RA, Wang B, Ji H, Kapp EA, Moritz RL, Zhu HJ and Simpson RJ: Secretome-based proteomic profiling of Ras-transformed MDCK cells reveals extracellular modulators of epithelial-mesenchymal transition. J Proteome Res 8: 2827-2837, 2009.

139. Lunter PC, van Kilsdonk JWJ, van Beek H, Cornelissen IMHA Bergers M, Willems PHGM, van Muijen GNP and Swart GWM: Activated leukocyte cell adhesion molecule (ALCAM/CD166/MEMD), a novel actor in invasive growth, controls matrix metalloproteinase activity. Cancer Res 65: 8801-8808, 2005.

140. Ofori-Acquah SF and King JA: Activated leukocyte cell adhesion molecule: A new paradox in cancer. Transl Res 151: 122-128, 2008.

141. Weidle UH, Eggle D, Klostermann S and Swart GWM: ALCAM/CD166: Cancer-related issues. Cancer Genomics Proteomics 7: 231-243, 2010.
142. von Lersner A, Droesen L and Zijlstra A: Modulation of cell adhesion and migration through regulation of the immunoglobulin superfamily member ALCAM/CD166. Clin Exp Metastasis 36: 87-95, 2019

143. Glentis A, Gurchenkov V and Matic Vignjevic D: Assembly, heterogeneity, and breaching of the basement membranes. Cell Adhes Migr 8: 236-245, 2014.

144. Pozzi A, Yurchenco PD and Iozzo RV: The nature and biology of basement membranes. Matrix Biol 57-58: 1-11, 2017.

145. Randles MJ, Humphries MJ and Lennon R: Proteomic definitions of basement membrane composition in health and disease. Matrix Biol 57-58: 12-28, 2017.

146. Zhou Y, Zhu Y, Fan X, Zhang C, Wang Y, Zhang L, Zhang H, Wen T, Zhang K, Huo X, et al: NID1, a new regulator of EMT required for metastasis and chemoresistance of ovarian cancer cells. Oncotarget 8: 33110-33121, 2017.

147. Pedrola N, Devis L, Llauradó M, Campoy I, Martinez-Garcia E, Garcia M, Muinelo-Romay L, Alonso-Alconada L, Abal M, Alameda F, et al: Nidogen 1 and Nuclear Protein 1: Novel targets of ETV5 transcription factor involved in endometrial cancer invasion. Clin Exp Metastasis 32: 467-478, 2015.

148. McMahon B and Kwaan HC: The plasminogen activator system and cancer. Pathophysiol Haemost Thromb 36: 184-194, 2008.

149. Durand MKV, Bødker JS, Christensen A, Dupont DM, Hansen M, Jensen JK, Kjelgaard S, Mathiasen L, Pedersen KE, Skeldal S, et al: Plasminogen activator inhibitor-I and tumour growth, invasion, and metastasis. Thromb Haemost 91: 438-449, 2004.

150. Sitaram RT, Mallikarjuna P, Landström M and Ljungberg B: Transforming growth factor- $\beta$ promotes aggressiveness and invasion of clear cell renal cell carcinoma. Oncotarget 7: 35917-35931, 2016.

151. Rabi ZA, Todorović-Raković N, Vujasinović T, Milovanović J and Nikolić-Vukosavljević D: Markers of progression and invasion in short term follow up of untreated breast cancer patients. Cancer Biomark 15: 745-754, 2015.

152. Rhone P, Ruszkowska-Ciastek B, Bielawski K, Brkic A, Zarychta E, Góralczyk B, Roszkowski K and Rość D: Comprehensive analysis of haemostatic profile depending on clinicopathological determinants in breast cancer patients. Biosci Rep 38: BSR20171657, 2018.

153. Li S, Wei X,He J,Tian X, Yuan S and Sun L: Plasminogen activator inhibitor-1 in cancer research. Biomed Pharmacother 105: 83-94, 2018.

154. Ochieng J, Nangami G, Sakwe A, Moye C, Alvarez J, Whalen D, Thomas P and Lammers P: Impact of Fetuin-A (AHSG) on tumor progression and type 2 diabetes. Int J Mol Sci 19: 2211, 2018.

155. Nangami GN, Watson K, Parker-Johnson K, Okereke KO, Sakwe A, Thompson P, Frimpong N and Ochieng J: Fetuin-A ( $\alpha 2 \mathrm{HS}$-glycoprotein) is a serum chemo-attractant that also promotes invasion of tumor cells through Matrigel. Biochem Biophys Res Commun 438: 660-665, 2013.

156. Watson K, Koumangoye R, Thompson P, Sakwe AM, Patel T, Pratap S and Ochieng J: Fetuin-A triggers the secretion of a novel set of exosomes in detached tumor cells that mediate their adhesion and spreading. FEBS Lett 586: 3458-3463, 2012.

157. Niu L, Song X, Wang N, Xue L, Song X and Xie L: Tumor-derived exosomal proteins as diagnostic biomarkers in non-small cell lung cancer. Cancer Sci 110: 433-442, 2019.

158. Adams GN, Rosenfeldt L, Frederick M, Miller W, Waltz D, Kombrinck K, McElhinney KE, Flick MJ, Monia BP, Revenko AS, et al: Colon cancer growth and dissemination relies upon thrombin, stromal PAR-1, and fibrinogen. Cancer Res 75: 4235-4243, 2015.

159. Honda K-I, Asada R, Kageyama K, Fukuda T, Terada H, Yasui T, Sumi T, Koyama M, Ishiko O and Sugawa T: Protein complex of fibrinogen gamma chain and complement factor $\mathrm{H}$ in ovarian cancer patient plasma. Anticancer Res 37: 2861-2866, 2017.

160. Duan S, Gong B, Wang P, Huang H, Luo L and Liu F: Novel prognostic biomarkers of gastric cancer based on gene expression microarray: COL12A1, GSTA3, FGA and FGG. Mol Med Rep 18: 3727-3736, 2018.

161. Zhang X, Wang F, Huang Y, Ke K, Zhao B, Chen L, Liao N, Wang L, Li Q, Liu X, et al: FGG promotes migration and invasion in hepatocellular carcinoma cells through activating epithelial to mesenchymal transition. Cancer Manag Res 11: 1653-1665, 2019.

162. Brakebusch $C$ and Fässler R: beta 1 integrin function in vivo: Adhesion, migration and more. Cancer Metastasis Rev 24: 403-411, 2005 . 
163.Pan B, Guo J, Liao Q and Zhao Y: $\beta 1$ and $\beta 3$ integrins in breast, prostate and pancreatic cancer: A novel implication (Review). Oncol Lett 15: 5412-5416, 2018.

164. Sun Q, Zhou C, Ma R, Guo Q, Huang H, Hao J, Liu H, Shi R and Liu B: Prognostic value of increased integrin-beta 1 expression in solid cancers: A meta-analysis. OncoTargets Ther 11: 1787-1799, 2018.

165. Albrektsen T, Richter HE, Clausen JT and Fleckner J: Identification of a novel integral plasma membrane protein induced during adipocyte differentiation. Biochem J 359: 393-402, 2001.

166.Pessentheiner AR, Huber K, Pelzmann HJ, Prokesch A, Radner FPW, Wolinski H, Lindroos-Christensen J, Hoefler G, Rülicke T, Birner-Gruenberger R, et al: APMAP interacts with lysyl oxidase-like proteins, and disruption of Apmap leads to beneficial visceral adipose tissue expansion. FASEB J 31: 4088-4103, 2017.

167. Gabriele C, Cantiello F, Nicastri A, Crocerossa F, Russo GI, Cicione A, Vartolomei MD, Ferro M, Morgia G, Lucarelli G, et al: High-throughput detection of low abundance sialylated glycoproteins in human serum by $\mathrm{TiO}_{2}$ enrichment and targeted LC-MS/MS analysis: Application to a prostate cancer sample set. Anal Bioanal Chem 411: 755-763, 2019.

168. Jiang S, Wang X, Song D, Liu X, Gu Y, Xu Z, Wang X, Zhang X, YeQ,Tong Z,et al: Cholesterol induces epithelial-to-mesenchymal transition of prostate cancer cells by suppressing degradation of EGFR through APMAP. Cancer Res 79: 3063-3075, 2019.

169. Moriyama-Kita M, Endo Y, Yonemura Y, Heizmann CW, Miyamori H, Sato H, Yamamoto E and Sasaki T: S100A4 regulates E-cadherin expression in oral squamous cell carcinoma. Cancer Lett 230: 211-218, 2005.

170. Shin J, Song I-S, Pak JH and Jang S-W: Upregulation of annexin A1 expression by butyrate in human melanoma cells induces invasion by inhibiting E-cadherin expression. Tumour Biol 37: 14577-14584, 2016.

171. Wong SHM, Fang CM, Chuah L-H, Leong CO and Ngai SC: E-cadherin: Its dysregulation in carcinogenesis and clinical implications. Crit Rev Oncol Hematol 121: 11-22, 2018.

172. Yu W, Wu J, Ning ZL, Liu QY and Quan RL: High expression of peroxiredoxin 1 is associated with epithelial-mesenchymal transition marker and poor prognosis in gastric cancer. Med Sci Monit 24: 2259-2270, 2018.

173. Kim S-Y: Cancer energy metabolism: Shutting power off cancer factory. Biomol Ther (Seoul) 26: 39-44, 2018.

174. Warburg O, Posener K and Negelein E: Über den stoffwechsel der carcinomzelle. Biochem Zeitschr 152: 309-344, 1924.

175. Chen T, Huang Z, Tian Y, Wang H, Ouyang P, Chen H, Wu L, Lin B and He R: Role of triosephosphate isomerase and downstream functional genes on gastric cancer. Oncol Rep 38: 1822-1832, 2017.

176. Lincet $\mathrm{H}$ and Icard P: How do glycolytic enzymes favour cancer cell proliferation by nonmetabolic functions? Oncogene 34 : 3751-3759, 2015.

177.Lone SN, Maqbool R, Parray FQ and Ul Hussain M: Triose-phosphate isomerase is a novel target of miR-22 and miR-28, with implications in tumorigenesis. J Cell Physiol 233: 8919-8929, 2018.

178. Menendez JA and Lupu R: Fatty acid synthase and the lipogenic phenotype in cancer pathogenesis. Nat Rev Cancer 7: 763-777, 2007.

179. Madigan AA, Rycyna KJ, Parwani AV, Datiri YJ, Basudan AM, Sobek KM, Cummings JL, Basse PH, Bacich DJ and O'Keefe DS: Novel nuclear localization of fatty acid synthase correlates with prostate cancer aggressiveness. Am J Pathol 184: 2156-2162, 2014

180. Wang H, Xi Q and Wu G: Fatty acid synthase regulates invasion and metastasis of colorectal cancer via Wnt signaling pathway. Cancer Med 5: 1599-1606, 2016.

181. Wen S, Niu Y, Lee SO, Yeh S, Shang Z, Gao H, Li Y, Chou F and Chang C: Targeting fatty acid synthase with ASC-J9 suppresses proliferation and invasion of prostate cancer cells. Mol Carcinog 55: 2278-2290, 2016.

182. Menendez JA and Lupu R: Fatty acid synthase (FASN) as a therapeutic target in breast cancer. Expert Opin Ther Targets 21: 1001-1016, 2017.

183.Zaidi N, Swinnen JV and Smans K: ATP-citrate lyase: A key player in cancer metabolism. Cancer Res 72: 3709-3714, 2012.

184. Cheng Y, Jia B, Wang Y and Wan S: miR-133b acts as a tumor suppressor and negatively regulates ATP citrate lyase via PPAR $\gamma$ in gastric cancer. Oncol Rep 38: 3220-3226, 2017.
185. Granchi C: ATP citrate lyase (ACLY) inhibitors: An anti-cancer strategy at the crossroads of glucose and lipid metabolism. Eur J Med Chem 157: 1276-1291, 2018

186. Icard $\mathrm{P}$ and Lincet $\mathrm{H}$ : The reduced concentration of citrate in cancer cells: An indicator of cancer aggressiveness and a possible therapeutic target. Drug Resist Updat 29: 47-53, 2016.

187. Nicolussi A, D'Inzeo S, Capalbo C, Giannini G and Coppa A: The role of peroxiredoxins in cancer. (Review) Mol Clin Oncol 6: 139-153, 2017

188. Veal E, Jackson T and Latimer H: Role/s of 'Antioxidant' enzymes in ageing. Subcell Biochem 90: 425-450, 2018.

189. Hampton MB, Vick KA, Skoko JJ and Neumann CA: Peroxiredoxin involvement in the initiation and progression of human cancer. Antioxid Redox Signal 28: 591-608, 2018.

190. Kang SW, Lee S and Lee JHS: Cancer-associated function of 2-Cys peroxiredoxin subtypes as a survival gatekeeper. Antioxidants 7: 161, 2018.

191. Forshaw TE, Holmila R, Nelson KJ, Lewis JE, Kemp ML, Tsang AW, Poole LB, Lowther WT and Furdui CM: Peroxiredoxins in cancer and response to radiation therapies. Antioxidants 8: 11, 2019.

192. Kim E-K,Lee SY,Kim Y, Ahn S-M and Jang HH: Peroxiredoxin 1 post-transcriptionally regulates snoRNA expression. Free Radic Biol Med 141: 1-9, 2019.

193. Dayton TL, Jacks T and Vander Heiden MG: PKM2, cancer metabolism, and the road ahead. EMBO Rep 17: 1721-1730, 2016.

194. Méndez-Lucas A, Li X, Hu J, Che L, Song X, Jia J, Wang J, Xie C, Driscoll PC, Tschaharganeh DF, et al: Glucose catabolism in liver tumors induced by c-MYC can be sustained by various PKM1/PKM2 ratios and pyruvate kinase activities. Cancer Res 77: 4355-4364, 2017.

195. Zhao Y, Butler EB and Tan M: Targeting cellular metabolism to improve cancer therapeutics. Cell Death Dis 4: e532, 2013.

196. Zhou W, Liotta LA and Petricoin EF: Cancer metabolism and mass spectrometry-based proteomics. Cancer Lett 356A: A176-A183, 2015.

197. Cheng T-Y, Yang Y-C, Wang H-P, Tien Y-W, Shun C-T, Huang H-Y, Hsiao M and Hua K-T: Pyruvate kinase M2 promotes pancreatic ductal adenocarcinoma invasion and metastasis through phosphorylation and stabilization of PAK2 protein. Oncogene 37: 1730-1742, 2018

198. Marchitti SA, Brocker C, Stagos D and Vasiliou V: Non-P450 aldehyde oxidizing enzymes: The aldehyde dehydrogenase superfamily. Expert Opin Drug Metab Toxicol 4: 697-720, 2008

199. Xu X, Chai S, Wang P, Zhang C, Yang Y, Yang Y and Wang K: Aldehyde dehydrogenases and cancer stem cells. Cancer Lett 369: 50-57, 2015 .

200. Zhou C and Sun B: The prognostic role of the cancer stem cell marker aldehyde dehydrogenase 1 in head and neck squamous cell carcinomas: A meta-analysis. Oral Oncol 50: 1144-1148, 2014.

201. Wei D, Peng J-J, Gao H, Zhang T, Tan Y and Hu Y-H: ALDH1 expression and the prognosis of lung cancer: A systematic review and meta-analysis. Heart Lung Circ 24: 780-788, 2015.

202. Li J, Zhang B, Yang YF, Jin J and Liu YH: Aldehyde dehydrogenase 1 as a predictor of the neoadjuvant chemotherapy response in breast cancer: A meta-analysis. Medicine (Baltimore) 97: e12056, 2018.

203. Dvorakova M, Nenutil R and Bouchal P: Transgelins, cytoskeletal proteins implicated in different aspects of cancer development. Expert Rev Proteomics 11: 149-165, 2014.

204. Rao D, Kimler BF, Nothnick WB, Davis MK, Fan F and Tawfik O: Transgelin: A potentially useful diagnostic marker differentially expressed in triple-negative and non-triple-negative breast cancers. Hum Pathol 46: 876-883, 2015.

205. Tan VY, Lewis SJ, Adams JC and Martin RM: Association of fascin-1 with mortality, disease progression and metastasis in carcinomas: A systematic review and meta-analysis. BMC Med 11: 52, 2013.

206. Iancu-Rubin C and Atweh GF: p27(Kip1) and stathmin share the stage for the first time. Trends Cell Biol 15: 346-348, 2005.

207. Belletti B and Baldassarre G: Stathmin: A protein with many tasks. New biomarker and potential target in cancer. Expert Opin Ther Targets 15: 1249-1266, 2011.

208. Biaoxue R, Hua L, Wenlong G and Shuanying Y: Overexpression of stathmin promotes metastasis and growth of malignant solid tumors: A systemic review and meta-analysis. Oncotarget 7: 78994-79007, 2016. 
209. Ding Z,Bae YH and Roy P: Molecularinsights on context-specific role of profilin-1 in cell migration. Cell Adhes Migr 6: 442-449, 2012.

210. Alkam D, Feldman EZ, Singh A and Kiaei M: Profilin1 biology and its mutation, actin(g) in disease. Cell Mol Life Sci 74: 967-981, 2017.

211. Jiang C, Ding Z, Joy M, Chakraborty S, Kim SH, Bottcher R, Condeelis J, Singh S and Roy P: A balanced level of profilin-1 promotes stemness and tumor-initiating potential of breast cancer cells. Cell Cycle 16: 2366-2373, 2017.

212. Wang Z, Shi Z, Zhang L, Zhang H and Zhang Y: Profilin 1, negatively regulated by microRNA-19a-3p, serves as a tumor suppressor in human hepatocellular carcinoma. Pathol Res Pract 215: 499-505, 2019.

213. Nakamura F, Stossel TP and Hartwig JH: The filamins: Organizers of cell structure and function. Cell Adhes Migr 5: 160-169, 2011

214. Savoy RM and Ghosh PM: The dual role of filamin A in cancer: Can't live with (too much of) it, can't live without it. Endocr Relat Cancer 20: R341-R356, 2013.

215. Shao Q-Q, Zhang T-P, Zhao W-J, Liu Z-W, You L, Zhou L, Guo J-C and Zhao Y-P: Filamin A: Insights into its exact role in cancers. Pathol Oncol Res 22: 245-252, 2016.

216. Wang Y, Liu S, Zhang Y and Yang J: Myosin heavy chain 9 Oncogene or tumor suppressor gene? Med Sci Monit 25: 888-892, 2019.

217.Desouza-Armstrong M, Gunning PW and Stehn JR: Tumor suppressor tropomyosin $\mathrm{Tpm} 2.1$ regulates sensitivity to apoptosis beyond anoikis characterized by changes in the levels of intrinsic apoptosis proteins. Cytoskeleton (Hoboken) 74 233-248, 2017

218. Ma Y, Xiao T, Xu Q, Shao X and Wang H: iTRAQ-based quantitative analysis of cancer-derived secretory proteome reveals TPM2 as a potential diagnostic biomarker of colorectal cancer. Front Med 10: 278-285, 2016.

219.Zhang J, Zhang J, Xu S, Zhang X, Wang P, Wu H, Xia B, Zhang G, Lei B, Wan L, et al: Hypoxia-induced TPM2 methylation is associated with chemoresistance and poor prognosis in breast cancer. Cell Physiol Biochem 45: 692-705, 2018.

220. Shin H, Kim D and Helfman DM: Tropomyosin isoform Tpm 2.1 regulates collective and amoeboid cell migration and cell aggregation in breast epithelial cells. Oncotarget 8: 95192-95205, 2017.

221. Mitchell CB, Black B, Sun F, Chrzanowski W, Cooper-White J, Maisonneuve B, Stringer B, Day B, Biro M and O'Neill GM Tropomyosin Tpm 2.1 loss induces glioblastoma spreading in soft brain-like environments. J Neurooncol 141: 303-313, 2019.

222. Shishkin S, Eremina L, Pashintseva N, Kovalev L and Kovaleva M: Cofilin-1 and other ADF/Cofilin superfamily members in human malignant cells. Int J Mol Sci 18: E10, 2016.

223. Gasparski AN, Ozarkar S and Beningo KA: Transient mechanical strain promotes the maturation of invadopodia and enhances cancer cell invasion in vitro. J Cell Sci 130: 1965-1978, 2017.

224. Tsai C-H, Lin L-T, Wang C-Y, Chiu Y-W, Chou Y-T, Chiu S-J, Wang H-E, Liu R-S, Wu C-Y, Chan P-C, et al: Over-expression of cofilin-1 suppressed growth and invasion of cancer cells is associated with up-regulation of let-7 microRNA. Biochim Biophys Acta 1852: 851-861, 2015.

225. Curto M and McClatchey AI: Ezrin...a metastatic detERMinant? Cancer Cell 5: 113-114, 2004

226. Haase G, Gavert N, Brabletz T and Ben-Zé'ev A: The Wnt target gene L1 in colon cancer invasion and metastasis. Cancers (Basel) 8: 48, 2016.

227. Cihan YB: Does ezrin play a predictive role in cancer patients undergoing radiotherapy and/or chemotherapy? Hum Pathol 80: 247-248, 2018

228. Mierke CT: The role of vinculin in the regulation of the mechanical properties of cells. Cell Biochem Biophys 53: $115-126,2009$.

229. Goldmann WH, Auernheimer V, Thievessen I and Fabry B: Vinculin, cell mechanics and tumour cell invasion. Cell Biol Int 37: 397-405, 2013.

230.Gao Y, Wang Z, Hao Q, Li W, Xu Y, Zhang J, Zhang W, Wang S, Liu S, Li M, et al: Loss of ER $\alpha$ induces amoeboid-like migration of breast cancer cells by downregulating vinculin. Nat Commun 8: 14483, 2017

231. Colombo E, Alcalay M and Pelicci PG: Nucleophosmin and its complex network: A possible therapeutic target in hematological diseases. Oncogene 30: 2595-2609, 2011.
232. Andersen JS, Wilkinson CJ, Mayor T, Mortensen P, Nigg EA and Mann M: Proteomic characterization of the human centrosome by protein correlation profiling. Nature 426: 570-574, 2003.

233. Box JK, Paquet N, Adams MN, Boucher D, Bolderson E, O'Byrne KJ and Richard DJ: Nucleophosmin: From structure and function to disease development. BMC Mol Biol 17: 19, 2016.

234. Werner MT, Zhao C, Zhang Q and Wasik MA: Nucleophosminanaplastic lymphoma kinase: The ultimate oncogene and therapeutic target. Blood 129: 823-831, 2017

235. Arrigo A-P: Mammalian HspB1 (Hsp27) is a molecular sensor linked to the physiology and environment of the cell. Cell Stress Chaperones 22: 517-529, 2017.

236. Xie Y-H, Li L-Y, He J-Z, Xu X-E, Liao L-D, Zhang Q, Xie J-J, $\mathrm{Xu}$ L-Y and Li E-M: Heat shock protein family B member 1 facilitates ezrin activation to control cell migration in esophageal squamous cell carcinoma. Int J Biochem Cell Biol 112: 79-87, 2019.

237. Honda K, Yamada T, Endo R, Ino Y, Gotoh M, Tsuda H, Yamada Y, Chiba H and Hirohashi S: Actinin-4, a novel actin-bundling protein associated with cell motility and cancer invasion. J Cell Biol 140: 1383-1393, 1998.

238. Hayashida Y, Honda K, Idogawa M, Ino Y, Ono M, Tsuchida A, Aoki T, Hirohashi S and Yamada T: E-cadherin regulates the association between beta-catenin and actinin-4. Cancer Res 65 : 8836-8845, 2005

239. Thomas DG and Robinson DN: The fifth sense: Mechanosensory regulation of alpha-actinin-4 and its relevance for cancer metastasis. Semin Cell Dev Biol 71: 68-74, 2017

240. Yamaguchi H, Ito Y, Miura N, Nagamura Y, Nakabo A, Fukami K, Honda K and Sakai R: Actinin-1 and actinin-4 play essential but distinct roles in invadopodia formation by carcinoma cells. Eur J Cell Biol 96: 685-694, 2017.

241. Keeling MC, Flores LR, Dodhy AH, Murray ER and Gavara N: Actomyosin and vimentin cytoskeletal networks regulate nuclear shape, mechanics and chromatin organization. Sci Rep7: 5219, 2017.

242. Battaglia RA, Delic S, Herrmann H and Snider NT: Vimentin on the move: new developments in cell migration. F1000 Res 7 (F1000 Faculty Rev): 1796, 2018.

243. Rao J and Li N: Microfilament actin remodeling as a potential target for cancer drug development. Curr Cancer Drug Targets 4: 345-354, 2004

244.Piktel E, Levental I, Durnaś B, Janmey PA and Bucki R: Plasma gelsolin: Indicator of inflammation and its potential as a diagnostic tool and therapeutic target. Int J Mol Sci 19: 2516, 2018.

245. Krishnakumar S, Sundaram A, Abhyankar D, KrishnamurthyV, Shanmugam MP, Gopal L, Sharma T and Biswas J: Major histocompatibility antigens and antigen-processing molecules in retinoblastoma. Cancer 100: 1059-1069, 2004

246. Okayama A, Miyagi Y, Oshita F, Nishi M, Nakamura Y, Nagashima Y, Akimoto K, Ryo A and Hirano H: Proteomic analysis of proteins related to prognosis of lung adenocarcinoma. J Proteome Res 13: 4686-4694, 2014.

247. Ryan D, Carberry S, Murphy AC, Lindner AU, Fay J, Hector S, McCawley N, Bacon O, Concannon CG, Kay EW, et al: Calnexin, an ER stress-induced protein, is a prognostic marker and potential therapeutic target in colorectal cancer. J Transl Med 14: 196, 2016.

248. Vogiatzi F, Brandt DT, Schneikert J, Fuchs J, Grikscheit K, Wanzel M, Pavlakis E, Charles JP, Timofeev O, Nist A, et al: Mutant p53 promotes tumor progression and metastasis by the endoplasmic reticulum UDPase ENTPD5. Proc Natl Acad Sci USA 113: E8433-E8442, 2016

249. Chen Y, Ma D, Wang X, Fang J, Liu X, Song J, Li X, Ren X, Li Q, Li Q, et al: Calnexin impairs the antitumor immunity of $\mathrm{CD}^{+}$and $\mathrm{CD}^{+} \mathrm{T}$ cells. Cancer Immunol Res 7: 123-135, 2018.

250.Dudek J, Benedix J, Cappel S, Greiner M, Jalal C, Müller L and Zimmermann R: Functions and pathologies of BiP and its interaction partners. Cell Mol Life Sci 66: 1556-1569, 2009.

251. Wang J, Lee J, Liem D and Ping P: HSPA5 Gene encoding $\mathrm{Hsp} 70$ chaperone $\mathrm{BiP}$ in the endoplasmic reticulum. Gene 618 : 14-23, 2017.

252. Herroon MK, Rajagurubandara E, Diedrich JD, Heath EI and Podgorski I: Adipocyte-activated oxidative and ER stress pathways promote tumor survival in bone via upregulation of Heme Oxygenase 1 and Survivin. Sci Rep 8: 40, 2018. 
253. Chen W, Do KC, Saxton B, Leng S, Filipczak P, Tessema M, Belinsky SA and Lin Y: Inhibition of the hexosamine biosynthesis pathway potentiates cisplatin cytotoxicity by decreasing $\mathrm{BiP}$ expression in non-small-cell lung cancer cells. Mol Carcinog 58: 1046-1055, 2019.

254. Sauk JJ, Nikitakis N and Siavash H: Hsp47 a novel collagen binding serpin chaperone, autoantigen and therapeutic target. Front Biosci 10: 107-118, 2005.

255. Duarte BDP and Bonatto D: The heat shock protein 47 as a potential biomarker and a therapeutic agent in cancer research. J Cancer Res Clin Oncol 144: 2319-2328, 2018.

256. Vatolin S, Phillips JG, Jha BK, Govindgari S, Hu J, Grabowski D, Parker Y, Lindner DJ, Zhong F, Distelhorst CW, et al: Novel protein disulfide isomerase inhibitor with anticancer activity in multiple myeloma. Cancer Res 76: 3340-3350, 2016.

257. Kuo T-F, Chen T-Y, Jiang S-T, Chen K-W, Chiang Y-M, Hsu Y-J, Liu Y-J, Chen H-M, Yokoyama KK, Tsai K-C, et al: Protein disulfide isomerase a4 acts as a novel regulator of cancer growth through the procaspase pathway. Oncogene 36: 5484-5496, 2017

258. Fucikova J, Kasikova L, Truxova I, Laco J, Skapa P, Ryska A and Spisek R: Relevance of the chaperone-like protein calreticulin for the biological behavior and clinical outcome of cancer. Immunol Lett 193: 25-34, 2018.

259. Sheng W, Chen C, Dong M, Wang G, Zhou J, Song H, Li Y, Zhang $J$ and Ding S: Calreticulin promotes EGF-induced EMT in pancreatic cancer cells via Integrin/EGFR-ERK/MAPK signaling pathway. Cell Death Dis 8: e3147, 2017.

260. Schcolnik-Cabrera A, Oldak B, Juárez M, Cruz-Rivera M, Flisser $\mathrm{A}$ and Mendlovic F: Calreticulin in phagocytosis and cancer: Opposite roles in immune response outcomes. Apoptosis 24: 245-255, 2019

261. Wang C, Jin G, Jin H, Wang N, Luo Q, Zhang Y, Gao D, Jiang K, Gu D, Shen Q, et al: Clusterin facilitates metastasis by EIF3I/Akt/MMP13 signaling in hepatocellular carcinoma. Oncotarget 6: 2903-2916, 2015.

262. Shapiro B, Tocci P, Haase G, Gavert N and Ben-Ze'ev A: Clusterin, a gene enriched in intestinal stem cells, is required for L1-mediated colon cancer metastasis. Oncotarget 6 : 34389-34401, 2015

263. Liu Y, Men C, Xu Y, Zhao K, Luo L, Dong D and Yu Q: Clusterin promotes growth and invasion of clear cell renal carcinoma cell by upregulation of S100A4 expression. Cancer Biomark 21 915-923, 2018

264. Tew KD, Manevich Y, Grek C, Xiong Y, Uys J and Townsend DM: The role of glutathione $\mathrm{S}$-transferase $\mathrm{P}$ in signaling pathways and S-glutathionylation in cancer. Free Radic Biol Med 51: 299-313, 2011

265. Wang Z, He W, Yang G, Wang J, Wang Z, Nesland JM, Holm R and Suo Z: Decreased expression of GST pi is correlated with a poor prognosis in human esophageal squamous carcinoma. BMC Cancer 10: 352, 2010.

266.Zannis-Hadjopoulos M, Yahyaoui W and Callejo M: 14-3-3 cruciform-binding proteins as regulators of eukaryotic DNA replication. Trends Biochem Sci 33: 44-50, 2008.

267. Bortner JD Jr, Das A, Umstead TM, Freeman WM, Somiari R, Aliaga C, Phelps DS and El-Bayoumy K: Down-regulation of 14-3-3 isoforms and annexin A5 proteins in lung adenocarcinoma induced by the tobacco-specific nitrosamine NNK in the $\mathrm{A} / \mathrm{J}$ mouse revealed by proteomic analysis. J Proteome Res 8: 4050-4061, 2009.

268.Leal MF, Calcagno DQ, Demachki S, Assumpcão PP, Chammas R, Burbano RR and Smith MA: Clinical implication of 14-3-3 epsilon expression in gastric cancer. World J Gastroenterol 18: 1531-1537, 2012.

269. Qiu Y, Zhou Z, Li Z, Lu L, Li L, Li X, Wang X and Zhang M: Pretreatment 14-3-3 epsilon level is predictive for advanced extranodal NK/T cell lymphoma therapeutic response to asparaginase-based chemotherapy. Proteomics Clin Appl 11: 3-4, 2017.

270. Bavelloni A, Piazzi M, Raffini M, Faenza I and Blalock WL: Prohibitin 2: At a communications crossroads. IUBMB Life 67 239-254, 2015

271. Mishra S and Nyomba BG: Prohibitin - At the crossroads of obesity-linked diabetes and cancer. Exp Biol Med (Maywood) 242: 1170-1177, 2017.

272. Taniguchi K, Matsumura K, Kageyama S, Ii H, Ashihara E, Chano T, Kawauchi A, Yoshiki T and Nakata S: Prohibitin-2 is a novel regulator of p21WAF1/CIP1 induced by depletion of $\gamma$-glutamylcyclotransferase. Biochem Biophys Res Commun 496: 218-224, 2018
273. Zhou Z, Ai H, Li K, Yao X, Zhu W, Liu L, Yu C, Song Z, Bao Y, Huang Y, et al: Prohibitin 2 localizes in nucleolus to regulate ribosomal RNA transcription and facilitate cell proliferation in RD cells. Sci Rep 8: 1479, 2018

274. Shen Y, Gao Y, Yuan H, Cao J, Jia B, Li M, Peng Y, Du X, Zhang $\mathrm{J}$ and Shi J: Prohibitin-2 negatively regulates AKT2 expression to promote prostate cancer cell migration. Int $\mathrm{J}$ Mol Med 41: 1147-1155, 2018

275. Yan C, Gong L, Chen L, Xu M, Abou-Hamdan H, Tang M, Désaubry L and Song Z: PHB2 (prohibitin 2) promotes PINK1-PRKN/Parkin-dependent mitophagy by the PARL-PGAM5-PINK1 axis. Autophagy 16: 419-434, 2020.

276. Jubran R, Kocsis J, Garam N, Maláti E, Gombos T, Barabás L, Gráf L, Prohászka Z and Fishelson Z: Circulating mitochondrial stress 70 protein/mortalin and cytosolic Hsp70 in blood: Risk indicators in colorectal cancer. Int J Cancer 141: 2329-2335, 2017.

277. Cruz IN, Coley HM, Kramer HB, Madhuri TK, Safuwan NAM, Angelino AR and Yang M: Proteomics analysis of ovarian cancer cell lines and tissues reveals drug resistance-associated proteins. Cancer Genomics Proteomics 14: 35-51, 2017.

278. Niu X, Su L, Qi S, Gao Z, Zhang Q and Zhang S: GRP75 modulates oncogenic Dbl-driven endocytosis derailed via the CHIP-mediated ubiquitin degradation pathway. Cell Death Dis 9: 971, 2018.

279. Chang HJ, Lee MR, Hong S-H, Yoo BC, Shin Y-K, Jeong JY, Lim S-B, Choi HS, Jeong S-Y and Park J-G: Identification of mitochondrial FoF1-ATP synthase involved in liver metastasis of colorectal cancer. Cancer Sci 98: 1184-1191, 2007.

280. Kühlbrandt W: Structure and mechanisms of F-type ATP synthases. Annu Rev Biochem 88: 515-549, 2019.

281.Liu J, Zhan X, Li M, Li G, Zhang P, Xiao Z, Shao M, Peng F, HuR and Chen Z: Mitochondrial proteomics of nasopharyngeal carcinoma metastasis. BMC Med Genomics 5: 62, 2012 .

282. Chen W-L, Kuo K-T, Chou T-Y, Chen C-L, Wang C-H, Wei Y-H and Wang L-S: The role of cytochrome $c$ oxidase subunit Va in non-small cell lung carcinoma cells: Association with migration, invasion and prediction of distant metastasis. BMC Cancer 12: 273,2012

283.Wang Y, Hu L, Zhang X, Zhao H, Xu H, Wei Y, Jiang H, Xie C, Zhou Y and Zhou F: Downregulation of mitochondrial single stranded DNA binding protein (SSBP1) induces mitochondrial dysfunction and increases the radiosensitivity in non-small cell lung cancer cells. J Cancer 8: 1400-1409, 2017.

284. Rajapakse A, Suraweera A, Boucher D, Naqi A, O'Byrne K, Richard DJ and Croft LV: Redox Regulation in the Base Excision Repair Pathway: Old and New Players as Cancer Therapeutic Targets. Curr Med Chem 27: 1901-1921, 2020

285. Croft LV, Bolderson E, Adams MN, El-Kamand S, Kariawasam R, Cubeddu L, Gamsjaeger R and Richard DJ: Human single-stranded DNA binding protein 1 (hSSB1, OBFC2B), a critical component of the DNA damage response. Semin Cell Dev Biol 86: 121-128, 2019.

286. Bozlu M, Orhan D, Baltaci S, Yaman O, Elhan AH, Tulunay O and Müftüioğlu YZ: The prognostic value of proliferating cell nuclear antigen, $\mathrm{Ki}-67$ and nucleolar organizer region in transitional cell carcinoma of the bladder. Int Urol Nephrol 33: 59-66, 2002

287. Maeda K, Chung Y-S, Onoda N, Ogawa M, Kato Y, Nitta A, Arimoto Y, Kondo Y, Arakawa T and Sowa M: Association of tumor cell proliferation with lymph node metastasis in early gastric cancer. Oncology 53: 1-5, 1996.

288. Ma S, Yang J, Li J and Song J: The clinical utility of the proliferating cell nuclear antigen expression in patients with hepatocellular carcinoma. Tumour Biol 37: 7405-7412, 2016.

289. Wang L, Kong W, Liu B and Zhang X: Proliferating cell nuclear antigen promotes cell proliferation and tumorigenesis by up-regulating STAT3 in non-small cell lung cancer. Biomed Pharmacother 104: 595-602, 2018.

290. Kato K, Kawashiri S, Yoshizawa K, Kitahara H, Okamune A, Sugiura S, Noguchi N and Yamamoto E: Expression form of $\mathrm{p} 53$ and PCNA at the invasive front in oral squamous cell carcinoma: Correlation with clinicopathological features and prognosis. J Oral Pathol Med 40: 693-698, 2011.

291. Dahl JA and Collas P: Q2ChIP, a quick and quantitative chromatin immunoprecipitation assay, unravels epigenetic dynamics of developmentally regulated genes in human carcinoma cells. Stem Cells 25: 1037-1046, 2007. 
292. Mahen R, Hattori H, Lee M, Sharma P, Jeyasekharan AD and Venkitaraman AR: A-type lamins maintain the positional stability of DNA damage repair foci in mammalian nuclei. PLoS One 8: e61893, 2013.

293. Sakthivel KM and Sehgal P: A novel role of lamins from genetic disease to cancer biomarkers. Oncol Rev 10: 309, 2016.

294.Kim J-K, Louhghalam A, Lee G, Schafer BW, Wirtz D and Kim D-H: Nuclear lamin A/C harnesses the perinuclear apical actin cables to protect nuclear morphology. Nat Commun 8: $2123,2017$.

295. Taheri F, Isbilir B, Müller G, Krieger JW, Chirico G, Langowski J and Tóth K: Random motion of chromatin is influenced by lamin A interconnections. Biophys J 114: 2465-2472, 2018.

296.Zuo L, Zhao H, Yang R, Wang L, Ma H, Xu X, Zhou P and Kong L: Lamin A/C might be involved in the EMT signalling pathway. Gene 663: 51-64, 2018.

297. Dmello C, Srivastava SS, Tiwari R, Chaudhari PR, Sawant S and Vaidya MM: Multifaceted role of keratins in epithelial cell differentiation and transformation. J Biosci 44: 33, 2019.

298. Sharma P, Alsharif S, Fallatah A and Chung BM: Intermediate filaments as effectors of cancer development and metastasis: A focus on keratins, vimentin, and nestin. Cells 8: 497, 2019.

299. Awe JA, Saranchuk J, Drachenberg D and Mai S: Filtration-based enrichment of circulating tumor cells from all prostate cancer risk groups. Urol Oncol 35: 300-309, 2017.

300.Erlandsson A, Forssell-Aronsson E, Seidal T and Bernhardt P Binding of TS1, an anti-keratin 8 antibody, in small-cell lung cancer after 177Lu-DOTA-Tyr3-octreotate treatment: A histological study in xenografted mice. EJNMMI Res 1: 19, 2011.

301. Sawant S, Vaidya M, Chaukar D, Gangadaran P, Singh AK, Rajadhyax S, Kannan S, Kane S, Pagare S and Kannan R: Clinicopathological features and prognostic implications of loss of $\mathrm{K} 5$ and gain of $\mathrm{K} 1, \mathrm{~K} 8$ and $\mathrm{K} 18$ in oral potentially malignant lesions and squamous cell carcinomas: An immunohistochemical analysis. Edorium J Tumor Biol 1: 1-22, 2014.

302. Alam H, Kundu ST, Dalal SN and Vaidya MM: Loss of keratins 8 and 18 leads to alterations in $\alpha 6 \beta 4$-integrin-mediated signalling and decreased neoplastic progression in an oral-tumour-derived cell line. J Cell Sci 124: 2096-2106, 2011.

303. Sun L and Fang J: Epigenetic regulation of epithelial-mesenchymal transition. Cell Mol Life Sci 73: 4493-4515, 2016.

304.Zhou B-R and Bai Y: Chromatin structures condensed by linker histones. Essays Biochem 63: 75-87, 2019.

305. Sridharan R, Gonzales-Cope M, Chronis C, Bonora G, McKee R, Huang C, Patel S, Lopez D, Mishra N, Pellegrini M, et al: Proteomic and genomic approaches reveal critical functions of $\mathrm{H} 3 \mathrm{~K} 9$ methylation and heterochromatin protein- $1 \gamma$ in reprogramming to pluripotency. Nat Cell Biol 15: 872-882, 2013.

306. Tzivion G, Gupta VS, Kaplun L and Balan V: 14-3-3 proteins as potential oncogenes. Semin Cancer Biol 16: 203-213, 2006.

307. Kurpińska A, Suraj J, Bonar E, Zakrzewska A, Stojak M, Sternak M, Jasztal A and Walczak M: Proteomic characterization of early lung response to breast cancer metastasis in mice. Exp Mol Pathol 107: 129-140, 2019.

308. Kawahara T, Hotta N, Ozawa Y, Kato S, Kano K, Yokoyama Y, Nagino M, Takahashi T and Yanagisawa K: Quantitative proteomic profiling identifies DPYSL3 as pancreatic ductal adenocarcinoma-associated molecule that regulates cell adhesion and migration by stabilization of focal adhesion complex. PLoS One 8: e79654, 2013.

309. Matsunuma R, Chan DW, Kim B-J, Singh P, Han A, Saltzman AB, Cheng C, Lei JT, Wang J, Roberto da Silva L, et al: DPYSL3 modulates mitosis, migration, and epithelial-to-mesenchymal transition in claudin-low breast cancer. Proc Natl Acad Sci USA 115: E11978-E11987, 2018.

310. Yang Y, Jiang Y, Xie D, Liu M, Song N, Zhu J, Fan J and Zhu C: Inhibition of cell-adhesion protein DPYSL3 promotes metastasis of lung cancer. Respir Res 19: 41, 2018.

311.Zarogoulidis P, Tsakiridis K, Karapantzou C, Lampaki S, Kioumis I, Pitsiou G, Papaiwannou A, Hohenforst-Schmidt W, Huang H, Kesisis G, et al: Use of proteins as biomarkers and their role in carcinogenesis. J Cancer 6: 9-18, 2015.

312. Frauchiger AL, Dummer R and Mangana J: Serum S100B levels in melanoma. Methods Mol Biol 1929: 691-700, 2019.
313. Yang T, Cheng J, You J, Yan B, Liu H and Li F: S100B promotes chemoresistance in ovarian cancer stem cells by regulating $\mathrm{p} 53$. Oncol Rep 40: 1574-1582, 2018.

314. Darlix A, Lamy P-J, Lopez-Crapez E, Braccini AL, Firmin N, Romieu G, Thezenas S and Jacot W: Serum HER2 extra-cellular domain, S100 $\beta$ and CA 15-3 levels are independent prognostic factors in metastatic breast cancer patients. BMC Cancer 16: $428,2016$.

315. Gao H, Zhang IY, Zhang L, Song Y, Liu S, Ren H, Liu H, Zhou H, Su Y, Yang Y, et al: S100B suppression alters polarization of infiltrating myeloid-derived cells in gliomas and inhibits tumor growth. Cancer Lett 439: 91-100, 2018.

316. Sadeghi M, Ordway B, Rafiei I, Borad P, Fang B, Koomen JL, Zhang C, Yoder S, Johnson J and Damaghi M: Integrative analysis of breast cancer cells reveals an epithelial-mesenchymal transition role in adaptation to acidic microenvironment. Front Oncol 10: 304, 2020.

317. Pampalakis G, Zingkou E, Sidiropoulos KG, Diamandis EP, Zoumpourlis V, Yousef GM and Sotiropoulou G: Biochemical pathways mediated by KLK6 protease in breast cancer. Mol Oncol 13: 2329-2343, 2019.

318. Seguella L, Capuano R, Pesce M, Annunziata G, Pesce M, de Conno B, Sarnelli G, Aurino L and Esposito G: S100B protein stimulates proliferation and angiogenic mediators release through RAGE/pAkt/mTOR pathway in human colon adenocarcinoma Caco-2 cells. Int J Mol Sci 20: 3240, 2019.

319. Méndez O, Peg V, Salvans C, Pujals M, Fernández Y, Abasolo I, Pérez J, Matres A, Valeri M, Gregori J, et al: Extracellular HMGA1 promotes tumor invasion and metastasis in triple-negative breast cancer. Clin Cancer Res 24: 6367-6382, 2018.

320. Wu X-J, Chen Y-Y, Gong C-C and Pei D-S: The role of high-mobility group protein box 1 in lung cancer. J Cell Biochem 119: 6354-6365, 2018

321. Sharma AK, Sharma VR, Gupta GK, Ashraf GM and Kamal MA: Advanced glycation end products (AGEs), glutathione and breast cancer: Factors, mechanism and therapeutic interventions. Curr Drug Metab 20: 65-71, 2019.

322. Schröter D and Höhn A: Role of advanced glycation end products in carcinogenesis and their therapeutic implications. Curr Pharm Des 24: 5245-5251, 2018

323. Palanissami G and Paul SFD: RAGE and its ligands: Molecular interplay between glycation, inflammation, and hallmarks of cancer - a review. Horm Cancer 9: 295-325, 2018.

324. Ahmad S, Khan H, Siddiqui Z, Khan MY, Rehman S, Shahab U, Godovikova T, Silnikov V and Moinuddin : AGEs, RAGEs and s-RAGE; friend or foe for cancer. Semin Cancer Biol 49: 44-55, 2018.

325. Thimmulappa RK, Mai KH, Srisuma S, Kensler TW, Yamamoto M and Biswal S: Identification of Nrf2-regulated genes induced by the chemopreventive agent sulforaphane by oligonucleotide microarray. Cancer Res 62: 5196-5203, 2002.

326. Sova M and Saso L: Design and development of Nrf2 modulators for cancer chemoprevention and therapy: A review. Drug Des Devel Ther 12: 3181-3197, 2018.

327. Taguchi $\mathrm{K}$ and Yamamoto M: The KEAP1-NRF2 system in cancer. Front Oncol 7: 85, 2017

328. Rojo de la Vega M, Chapman E and Zhang DD: NRF2 and the hallmarks of cancer. Cancer Cell 34: 21-43, 2018.

329. Lignitto L, LeBoeuf SE, Homer H, Jiang S, Askenazi M, Karakousi TR, Pass HI, Bhutkar AJ, Tsirigos A, Ueberheide B, et al: Nrf2 activation promotes lung cancer metastasis by inhibiting the degradation of Bach1. Cell 178: 316-329.e18, 2019

330. Wiel C, Le Gal K, Ibrahim MX, Jahangir CA, Kashif M, Yao H, Ziegler DV, Xu X, Ghosh T, Mondal T, et al: BACH1 stabilization by antioxidants stimulates lung cancer metastasis. Cell 178: 330-345.e22, 2019.

331. Ryoo IG, Choi BH, Ku S-K and Kwak M-K: High CD44 expression mediates p62-associated NFE2L2/NRF2 activation in breast cancer stem cell-like cells: Implications for cancer stem cell resistance. Redox Biol 17: 246-258, 2018.

This work is licensed under a Creative Commons Attribution-NonCommercial-NoDerivatives 4.0 International (CC BY-NC-ND 4.0) License. 